NBSIR 81-2442

\title{
Technical Activities 1981 Office of Standard Reference Data
}

U.S. DEPARTMENT OF COMMERCE

National Bureau of Standards

National Measurement Laboratory

Washington, DC 20234

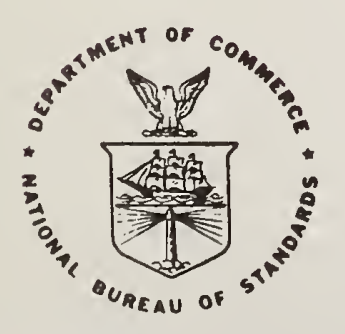

$-Q C \quad$ DEPARTMENT OF COMMERCE

100

IONAL BUREAU OF STANDARDS

, 456

$31-2442$

1931

$c, 2$ 

U.S. DEPARTMENT OF COMMERCE

National Bureau of Standards

National Measurement Laboratory

Washington, DC 20234

December 1981

U.S. DEPARTMENT OF COMMERCE, Malcolm Baldrige, Secretary NATIONAL BUREAU OF STANDARDS, Ernest Ambler, Director 


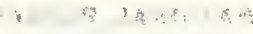

menton

(5) 
The Office of Standard Reference Data is one of six program offices in the National Measurement Laboratory, National Bureau of Standards. The Standard Reference Data Program develops and disseminates data bases of critically evaluated physical/chemical properties of substances. These data bases are available through NBS and private publications, on magnetic tape, and from on-line retrieval systems.

The Office of Standard Reference Data is responsible for management and coordination of the program. Work is carried out through a decentralized network of data centers and projects referred to as the National Standard Reference Data System (NSRDS). This volume summarizes the activities of the program for the year 1981.

Key words: data compilation; energy and environmental data; evaluated data; materials data; standard reference data; technical activities 1981; thermochemical and thermophysical data 

Introduction ..................... 1

Program Structure .............. . . 3

Energy and Environmental Data ............ 5

Industrial Process Data ............... . . 9

Materials Properties Data . . . . . . . . . . . . 14

Automation .................. 19

Data Center and Project Reports . . . . . . . . . 23

Data Centers ............... . . 24

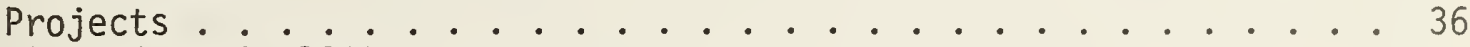

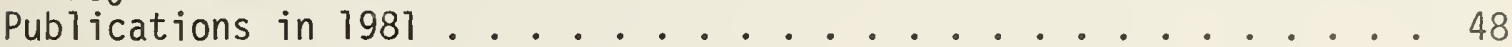

Publications Scheduled for 1982 . . . . . . . . . 53

\section{APPENDICES}

A. List of Acronyms and Abbreviations . . . . . . . . 57

B. OSRD Organization Chart ............ 59

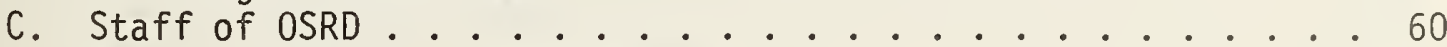

D. Papers Published by OSRD Staff . . . . . . . . 63

E. Invited Talks and Presentations by OSRD Staff . . . . . 64

F. Technical and Professional Committee

Participation and Leadership........... . 66

G. NBS Seminars Sponsored by OSRD ........... 69

H. Standard Reference Data Act (PL 90-396) . . . . . . . . 70

I. NSRDS Data Centers .............. . 72

J. NBS Organization Chart ............ 77

K. NML Organization Chart ............ 78 

The Office of Standard Reference Data is responsible for program management and coordination of the National Standard Reference Data System (NSRDS). The forma 1 existence of the NSRDS dates from 1963, when the Federal Council for Science and Technology asked the National Bureau of Standards to assume primary responsibility in the Federal Government for promoting and coordinating the critical evaluation of numerical data in the physical sciences. The program was conceived as a decentralized national effort, with financial support coming from a variety of Government and private sources, but with NBS responsible for the overall planning and coordination. In 1968 the Congress provided a specific

legislative mandate for the program through passage of Public Law 90-396, the Standard Reference Data Act.* This act states the policy of the Congress to make reliable reference data available to scientists, engineers, and the general public, and it encourages cooperation among NBS, other Federal Agencies, and the private sector in meeting this objective.

The technical scope of the program gives primary emphasis to we11defined physical and chemical properties of substances and systems which are well characterized. Also included are materials of commerce (alloys, ceramics, etc.) whose composition may vary only within clearly stated ranges. Materials of uncertain or widely variable composition are not included. Properties which depend upon arbitrarily defined characteristics of the measurement technique are generally excluded. While these definitions leave many borderline cases, the overall intent is to concentrate the effort on intrinsic properties that are clearly defined in terms of accepted physical theory and substances whose composition and history are so well known as to justify evaluation of the data. Biological properties and data relating to large natural systems (e.g., the atmosphere, the oceans) also fall outside the program.

The major aim of the program is to provide critically evaluated numerical data to the scientific and technical community in a convenient and accessible form. Certain secondary outputs, such an annotated bibliographies and procedures for computerized handling of data, are also made available. A second aim is to provide feedback into experimental programs to help raise the general standards of measurement. That is, by communicating the experience gained in evaluating the world output of data in the physical sciences, NSRDS helps to advance the level of experimental techniques and improve the reliability of physical measurements.

The Office of Standard Reference Data monitors and coordinates the work of the various data centers and specialized projects which collectively make up the NSRDS. These projects are located in the technical

*See Appendix $\mathrm{H}$. 
divisions of NBS and in universities, industrial laboratories, and other Government laboratories. Close association between data evaluation projects and relevant experimental research programs helps provide the critical judgment which is essential to assure the reliability of the final output.

The principal output of the program consists of compilations of evaluated data and critical reviews of the status of data in particular technical areas. Evaluation of data implies a careful examination, by an experienced specialist, of all published measurements of the quantity in question, leading to the selection of a recommended value and a statement concerning its accuracy or reliability. The techniques of evaluation depend upon the data in question, but generally include an examination of the method of measurement and the characterization of the materials, a comparison with relevant data on other properties and materials, and a check for consistency with theoretical relationships. Adequate documentation is provided for the selections of recommended values and accuracy estimates.

Evaluated data produced under the NSRDS program are disseminated through the following mechanisms:

Journal of Physical and Chemical Reference Data - A quarterly journal containing data compilations and critical data reviews, published for the National Bureau of Standards by the American Institute of Physics and the American Chemical Society.

NSRDS-NBS Series - A publication series distributed by the Superintendent of Documents, U.S. Government Printing Office.

Appropriate publications of technical societies and commercial publishers.

Magnetic tapes, on-line networks, and other computer-based formats .

Response by OSRD and individual data centers to inquiries for specific data. 
Current activities in the Standard Reference Data program are carried out in 25 data centers and approximately 35 short-term projects located in the technical divisions of NBS and in academic and industrial laboratories. Each of these projects undertakes the collection and evaluation of the available data on a specified set of properties and substances. The projects are aggregated into three application-oriented program areas:

Energy and Environmental Data - Includes data from fields such as chemical kinetics, spectroscopy, and radiation physics and chemistry which have application to energy-related R\&D and environmental monitoring and modeling.

Industrial Process Data - Covers primarily thermodynamic and transport properties of substances important to the chemical and related industries.

Materials Properties Data - Includes structural, electrical, optical, and mechanical properties of solid materials of broad interest.

Since comprehensive coverage of all properties and materials of importance in these three program areas is not feasible, the Office of Standard Reference Data (OSRD) attempts to select the data sets of highest priority, based upon the present and anticipated applications of the data. The current focus in each area is described in the sections below.

In addition to its planning and coordinating role, OSRD is responsible for dissemination of the results from the projects that it supports. The principal means of dissemination is still hard-copy publications, although computer-based distribution is becoming more important, as described below. Response to specific inquries for data directed to OSRD and the individual data centers forms another dissemination mode.

The following tables summarize the published output of the program and the distribution of this output:

\section{Publications in 1981}

\begin{tabular}{|c|c|c|}
\hline Series & Published & Titles Published \\
\hline JPCRD, Vol. 10 & 1911 & 22 \\
\hline NSRDS-NBS Series & 1061 & 3 \\
\hline $\begin{array}{l}\text { Data Compilations in } \\
\text { other NBS series }\end{array}$ & 1535 & 10 \\
\hline $\begin{array}{l}\text { Data Compilations from } \\
\text { other publishers }\end{array}$ & 1255 & 5 \\
\hline $\begin{array}{l}\text { Bibliographies and } \\
\text { Indexes in NBS series }\end{array}$ & 372 & 2 \\
\hline $\begin{array}{l}\text { Bibliographies and } \\
\text { Indexes from other pubs. }\end{array}$ & 1408 & 3 \\
\hline Totals & 7542 & 45 \\
\hline
\end{tabular}


Subscribers to JPCRD

\begin{tabular}{lc} 
Month/Year & $\frac{\text { Number }}{1156}$ \\
\hline $9 / 1977$ & 1205 \\
$9 / 1978$ & 1237 \\
$9 / 1979$ & 1234 \\
$9 / 1980$ & 1265
\end{tabular}

Inquiries Received in OSRD

(Does not include inquiries received by data centers.)

$\begin{array}{lc}\text { Year } & \text { Number } \\ 1977 & 530 \\ 1978 & 730 \\ 1979 & 882 \\ 1980 & 787 \\ 1987 * & 765\end{array}$

Sales of JPCRD Offprints and Supplements

$\begin{array}{lcc}\text { Year } & \text { Offprints } & \text { Supplements } \\ 1977 & 4078 & 567 * * \\ 1978 & 5577 & 184 \\ 1979 & 5981 & 137 \\ 1980 & 5079 & 117 \\ 1987 * & 4453 & 77\end{array}$

* Projected to end of year.

** New supplement issued in 1977. 
L. H. Gevantman, Program Manager

The scope and objectives of this program within the Office of standard Reference Data (OSRD) are to contribute to the solution of national energy and environmental problems by providing government and industry with properly evaluated physical and chemical data. These data bases go to support the more effective use of present energy sources and the development of new sources while helping to protect public health and safety through the improvement of environmental quality.

Program effort is directed toward the compilation, evaluation, and dissemination of physical property data on materials which produce, conserve, and store energy. The program's impact on the national scene covers a wide spectrum and includes such applications as modeling combustion processes for increased energy efficiency, designing improved batteries for energy storage, and developing new materials and systems for use in energy production such as fusion energy.

Similarly, the provision of physical property data on environmental pollutant behavior makes an important contribution toward improving air and water quality. Again, the impact is felt nationally because these data support industry's efforts to meet clean air and water regulations as well as improve health and safety in chemical manufacturing activities. Moreover, they contribute to governmental (federal, state, and local) attempts both to regulate and clean up the Nation's environment.

The data required span most of the disciplinary areas embraced by the OSRD but emphasize the fields of kinetics, thermodynamics, and atomic and molecular science. The work of compiling and disseminating these data is performed within eleven data centers supported partially or totally by the OSRD. In addition, a number of grants have been awarded for short-term data projects to enlarge the scope of the program.

The activities within the program over the past year have been many. The series on physical properties data for energy conservation has produced two more volumes which should see publication in 1982. Another manuscript, completing the series, is now being written. High temperature data related to combustion kinetics have also been published, and fifteen data sheets related to jet and rocket propulsion kinetics have been completed.

In support of fusion energy, programmatic progress continues in the issuance of atomic energy level data on the transition metals, and data on atomic transition probabilities for this same series are nearing manuscript stage for publication in 1982. Two data centers have been merged to form the Photon and Charged Particle Data Center within the NBS Center for Radiation Research. A budget initiative, which would have enlarged the scope of this newly-formed data center, was prepared in collaboration with the Center for Radiation Research, but has so far been unsuccessful. 
The OSRD under the sponsorship of the Office of Nuclear Waste Isolation (ONWI)-Battelle has joined with the U.S. Geological Survey's National Center for Thermodynamic Data of Minerals and Purdue University's Center for Information and Numerical Data Analysis and Synthesis (CINDAS) to produce evaluated physical properties data on the geological materials identified as prime candidates in which to bury high-level nuclear wastes. Two publications have been issued.

Continued interaction with the Joint Committee on Atomic and Molecular Physical Data (JCAMP) has resulted in a new method for codifying infrared spectra. Furthermore, cooperation with the National Institutes of Health (NIH) and the Environmental Protection Agency (EPA) has initiated a study which should lead to the establishment of an on-line evaluated infrared data file on the Chemical Information System (CIS). The initial tests for producing acceptable spectra in digitized form are now in progress. The plan calls for close cooperation with the Coblentz Society which will monitor the quality of the spectra.

Emphasis on solubility data has resulted from the close relationship enjoyed between members of the International Union of Pure and Applied Chemistry (IUPAC) Commission V.8 and OSRD. A new data center on solubility data has recently been established at Emory University under the direction of Professor H. L. Clever.

Considerable progress has been achieved in the issuance of data related to solution-phase photochemical kinetics since enlarging the scope of the Radiation Chemistry Data Center (RCDC). In addition, an update of the data sheets on gas phase reactions in the atmosphere has been completed and will be published in 1982 .

While the present direction of the program is considered satisfactory, changes or additions will be sought consonant with the needs expressed by industry and government. Thus, the budget initiative on the interaction of radiation with matter will again be submitted for implementation. Redirection of the Chemical Kinetics Data Center to emphasize solution kinetics more heavily is under consideration. Physical property data for a new geological material, namely basalt, will be evaluated and published. The high temperature kinetic data sheets will be extended to hydrocarbon-radical reactions. The Ion Energetics Data Center will begin the evaluation of heats of formation of ions with a subsequent look at ion-kinetics data evaluation. Further involvement in the growth of on-line evaluated data files will necessitate important concerns for the quality of data entering such files. Considerable interaction is anticipated among the OSRD, NIH, EPA, and other groups who are concerned with this problem. 
PUBLICATIONS IN 1981: Energy Levels of Sodium, $\mathrm{Na}$ I through $\mathrm{Na}$ XI, W. C. Martin and Romuald Zalabas, JPCRD Vo1. 10, No. 1, pp. 153-196.

Energy Levels of Nickel, $\mathrm{Ni}$ I through $\mathrm{Ni}$ XXVIII, Charles Corl iss and Jack Sugar, JPCRD Vol. 10, No. 1, pp. 197-289.

Atomic Transition Probabilities for Iron, Cobalt, and Nickel (A Critical Data Compilation of Allowed Lines, J. R. Fuhr, G. A. Martin, W. L. Wiese, and S. M. Younger, JPCRD Vol. 10, No. 2, pp. 305-565.

A Critical Review of Henry's Law Constants for Chemicals of Environmental Interest, Donald Mackay and Wan Ying Shiu, JPCRD Vol. 10, No. 4.

Rate Constants for the Decay and Reactions of the Lowest Electronically Excited Singlet State of Molecular Oxygen in Solution, Francis Wilkinson and James Brummer, JPCRD VoT. 10, No. 4.

Tables of $\mathrm{N}_{2} \mathrm{O}$ Absorption Lines for the Calibration of Tunable Infrared Lasers from $522 \mathrm{~cm}^{-1}$ to $657 \mathrm{~cm}^{-1}$ and from $1115 \mathrm{~cm}^{-1}$ to $1340 \mathrm{~cm}^{-1}, W$. B. 01 son, A. G. Maki, W. J. Lafferty, JPCRD Vol. 10, No. 4.

Energy Levels of Cobalt, Co I through Co XXVII, Jack Sugar and Charles Corliss, JPCRD Vol. 10, No. 4.

Evaluated Kinetic Data for High Temperature Reactions Volume 4 Homogeneous Gas Phase Reactions of Halogen- and Cyanide-Containing Species, D. L. Baulch, J. Duxbury, S. J. Grant, D. C. Montague, JPCRD Vol. 10, Supplement No. 1.

Microwave Spectra of Molecules of Astrophysical Interest. XX. Methane, I. Ozier, M. C. L. Gerry, and A. G. Robiette, JPCRD Vol. 10, No. 4.

Physical Properties Data Compilations Relevant to Energy Storage. IV. Molten Salts: Data on Additional Single and Multi-Component Salt Systems, G. J. Janz and R. P. T. Tomkins, NSRDS-NBS 61, Part IV. 
Physical Properties Data Compilations Relevant to Energy Storage. V. Mechanical Properties Data on Alloys for Use in Flywheels, H. M. Ledbetter, NSRDS-NBS 61, Part V.

Optical Spectra of Nonmetallic Inorganic Transient Species in Aqueous Solution, Gordon L. Hug, NSRDS-NBS 69.

Data Index for Energy Transfer Collisions of Atoms and Molecules - 1970-1979, J. W. GalTagher, Janet Van Blerkom, E. C. Beaty, J. R. Rumbie, Jr., NBS Spec. Pub. 593.

Physical Properties Data for Rock Salt, L. H. Gevantman, Editor, NBS Monograph 167.

Feasibility Study: Compilation and Evaluation of Properties Data for Basalt, Granite, Tuff, and ShaTe, L. H. Gevantman, NBSIR 81-2217.

BiweekTy List of Papers on Radiation Chemistry and Photochemistry, Annual Cumulation with Keyword and Author Indexes, Vol. 13, 1980, Radiation Chemistry Data Center.

Biweekly List of Papers on Radiation Chemistry and Photochemistry, Vo1. 14, 1981, Radiation Chemistry Data Center. 
H. J. White, Jr., Program Manager

This portion of the overall OSRD program is focused on the needs of industry in developing, designing, and operating plant processes. Major emphasis is placed on the chemical and petrochemical industries.

This is a very active field at the present time. Rapidly changing energy and feedstock costs and mandated safety and pollution control requirements have led to the introduction of many new processes and the redesign or improvement of many old ones.

Analyses of chemical operations and surveys of industrial scientists and engineers have shown that the properties most frequently needed in process design are the thermodynamic and transport properties of the substances and mixtures being processed. This is reflected in the structure of this program which is primarily composed of projects to produce reference data in these areas.

It is obvious that the activities in the programs on Energy and Environmental Data and Materials Properties will develop data of importance in industrial process design. The Industrial Process Data program is designed to coordinate with and reinforce these other OSRD programs.

Thermodynamics data can be roughly divided into those that describe chemical reactions and those that describe the behavior of non-reacting substances or mixtures when the temperature, pressure, and--for mixtures-composition are changed. These can be called thermochemical properties and thermophysical properties, respectively, and the program is roughly divided into these two parts. The most frequently needed transport properties are the thermal conductivities of solids and fluids and the viscosities of fluids. The transport properties are classified as thermophysical properties.

Thermochemical properties will be considered first. Since changes in thermodynamic state functions are dependent only on the initial and final states and not on the path between, it is possible and convenient to consider all chemical reactions at one standard temperature and pressure and to use auxiliary calculations to describe the changes in the reactants and products on going from the desired reaction conditions to the standard conditions.

The task of providing data describing reactions at the standard conditions is covered by the Chemical Thermodynamics Data Center at NBS for inorganic and simple organic substances, with additional work on organic substances provided by the Thermodynamics Research Center at Texas A \& $M$ and on some specific substances provided by the JANAF group at Dow Chemical. The magnitude of this task can be appreciated from the fact that the NBS Tech Note 270 series, an output from the Chemical Thermodynamics Data Center, contains 26,000 property yalues involving 14,300 substances. The Aqueous Electrolyte Data Center works 
closely with the Chemical Thermodynamics Data Center, providing data needed in describing reactions in solution. These data describing the properties of aqueous electrolyte solutions have a large range of additional uses as well.

At the present time all groups around the world providing data to describe chemical reactions work independently. Given the size of the task, the potential advantages of cooperation are great. However, in addition to the managerial problems that are common to al1 widespread, decentralized, cooperative ventures, there are severe technical problems to be solved, some involving magnitude (the Tech Note 270 series covers 60,000 references), and some thermodynamic in nature. Use of computers appears to offer methods for solving these technical problems, and much effort has been given to developing appropriate automated techniques. The further task of designing an international system is being worked on in cooperation with the CODATA Task Group on Internationalization and Systematization of Thermodynamic Tables. Additional effort is involved in preparing to provide chemical thermodynamic data on the Chemical Information System.

The largest portion of the thermophysical properties area is devoted to preparing critically evaluated data on the thermodynamic properties of pure substances and their mixtures. Although the majority of industrial process streams are mixtures, the data for pure substances are valuable in their own right and form the base for the prediction and expression of behavior of mixtures.

The program involves two major efforts to provide evaluated data for mixtures, one at the Fluid Mixtures Data Center at NBS Boulder Laboratories and one at the Thermodynamic Research Laboratory at Washington University in St. Louis. In addition, the Polar Fluids Data Project at NBS is beginning to transfer its focus to mixtures. All three projects are concerned with pure fluids as well.

Two major projects on pure fluids are reaching completion. The Polar Fluids Data Project has prepared a formulation for the Helmholtz energy of water which provides representations for the density and other thermodynamic properties from the solid/fluid line to $1000^{\circ} \mathrm{C}$ and from 0 to $1 \mathrm{GPa}$. The representations are remarkably accurate, almost invariably within the estimated accuracy of the best data available. This formulation is being considered by the International Association for the Properties of Steam (IAPS) as a replacement for its IFC 1968 Formulation for Scientific and General Use. The Fluid Mixtures Data Center is preparing a monograph which contains formulations for the thermodynamic and transport properties of a number of industrial fluids. These formulations cover a wide range of temperature and pressure and are sufficiently similar that using them on a computer should be greatly simplified.

The transport properties of solids and fluids are being evaluated by the Center for Numerical Data Analysis and Synthesis (CINDAS) at Purdue University. 
The Design Institute for Physical Properties Data (DIPPR) of the AIChE is a cooperative industrial program which sponsors a number of projects to produce reference data. The OSRD program on Industrial Process Data cooperates closely with DIPPR. It sponsors DIPPR projects and also acts to carry out projects for DIPPR. The program is also coordinated with that of the IUPAC Thermodynamic Tables Project.

The future should see the continuation of the major effort to automate the procedures in the thermochemical area. This is necessary if a system of international cooperation in evaluation is to be put in place. The major components of an international system have been established, but much work remains before a working international system is operational. The Chemical Thermodynamics Data Center and the JANAF Project would be major components in such a system.

In the thermophysical area increased effort is to be expected in the field of mixtures. At the present time there are serious technical problems to be solved, in addition to a substantial body of experimental data to be treated.

In both areas increasing attention to data prediction can be anticipated.

PUBLICATIONS IN 1981: Evaluated Activity and Osmotic Coefficients for Aqueous Solutions: Bi-Univalent Compounds of Zinc, Cadmium, and Ethylene Bis (Trimethylammonium) Chloride and Iodide, Robert N. Goldberg, JPCRD Vol. 10, No. 1, pp. 1-55.

Tables of the Dynamic and Kinematic Viscosity of Aqueous KCT Solutions in the Temperature Range 25-150 ${ }^{\circ} \mathrm{C}$ and the Pressure Range 0.1-35 MPa, Joseph Kestin, H. Ezzat Khalifa, and Robert $\mathrm{J}$. Correia, JPCRD Vol. 10, No. 1, pp. 57-70.

Tables of the Dynamic and Kinematic Viscosity of Aqueous $\mathrm{NaCl}$ Solutions in the Temperature Range 20-150 ${ }^{\circ} \mathrm{C}$ and the Pressure Range 0.1-35 $\mathrm{MPa}$, Joseph Kestin, H. Ezzat Khalifa, and Robert J. Correia, JPCRD Vol. 10, No. 1, pp. 71-87.

Heat Capacity and Other Thermodynamic Properties of Linear Macromolecules. I. Selenium, Umesh Gaur, Hua-Cheng Shu, Aspy Mehta, and Bernhard Wunderlich, JPCRD Vol. 10, No. 1, pp. 89-117.

Heat Capacity and Other Thermodynamic Properties of Linear Macromolecules. II. Polyethylene, Umesh Gaur and Bernhard Wunderlich, JPCRD Vo 1. 10, No. 1, pp. 119-152. 
Ion Product of Water Substance, $0-1000{ }^{\circ} \mathrm{C}$, $1-10,000$ Bars, New International Formulation and Its Background, William L. Marsha 17 and E. U. Franck, JPCRD Vol. 10, No. 2, pp. 295-304.

Thermodynamic Tabulations for Selected Phases in the Systems $\mathrm{CaO}-\mathrm{Al}_{2} \mathrm{O}_{3}-\mathrm{SiO}_{2}-\mathrm{H}_{2} \mathrm{O}$ at $107.325 \mathrm{kPa}$ (1 atm) between 273.15 and $7800 \mathrm{~K}$, John L. Haas, Jr., Gilpin R. Robinson, Jr., and Bruce S. Hemingway, JPCRD Vol. 10, No. 3, pp. 575-699.

Evaluated Activity and Osmotic Coefficients for Aqueous Solutions: Thirty-Six Uni-Bivalent Electrolytes, Robert N. Goldberg, JPCRD VoT. 10, No. 3, pp. 671-765.

Activity and 0smotic Coefficients of Aqueous ATkali Metal Nitrites, Bert R. Staples, JPCRD Vol. 10, No. 3, pp. 767-778.

Activity and Osmotic Coefficients of Aqueous Sulfuric Acid at $298.15 \mathrm{~K}$, Bert R. Staples, JPCRD Vo1. 10, No. 3, pp. 779-798.

Heat Capacity and Other Derived Thermodynamic Properties of Linear Macromolecules. III. Polyoxides, Umesh Gaur and Bernhard Wunderlich, JPCRD Vol. 10, No. 4.

Heat Capacity and Other Thermodynamic Properties of Linear Macromolecules. IV. Polypropylene, Umesh Gaur and Bernhard Wunderlich, JPCRD VoT. 10, No. 4.

The Critical Region Equation of State of Ethylene and the Effect of Small Impurities, J. R. Hastings, J. M. H. Levelt Sengers, and F. W. Balfour,

J. Chem. Thermodynamics 12, 1009 (1980).

Selected Values of Chemical Thermodynamic Properties, Compounds of Uranium, Protactinium, Thorium, Actinium, and the A7kali Meta7s, D. D. Wagman, W. H. Evans, V. B. Parker, R. H. Schumm, and

R. L. Nutta11, NBS Technical Note 270-8.

An Equation of State for Fluid Ethylene, R. D. McCarty and R. T. Jacobsen, NBS Technical Note 1045. 
Thermodynamic Properties of Miscellaneous Materials, Eugene S. Domalski, William H. Evans, and Thomas L. Jobe, Jr., NBSIR 78-1479.

Tables of Experimental Rate Constants for Chemical Reactions Occurring in Combustion (1971-1977), Francis West7ey, NBSIR 81-2254.

Chemical Thermodynamic Data Banks, David Garvin, Vivian B. Parker, and Donald D. Wagman, NBSIR $81-$ 2347.

A Report on Thermodynamic Data for Desulfurization Processes, V. B. Parker, B. R. Staples, T. L. Jobe, Jr., and D. Neumann, NBSIR 81-2345.

Bulletin of Chemical Thermodynamics, Vol. 24, 1981, IUPAC Commission on Thermodynamics and Thermochemistry, Robert D. Freeman, Editor. 
J.R. Rumble, Jr., Program Manager

The Materials Properties Data Program has been designed to provide evaluated materials property data to the U.S. materials industry and materials researchers. The program presentiy concentrates on three areas-phase stability information, crystallographic data, and diffusion data--and has profited by a number of close-working agreements with various industrial groups.

\section{Phase Stability Information}

Phase stability information is basic to a better understanding of materials and their properties and is needed to develop and design new alloys, ceramics, and metallic/nonmetallic systems. OSRD supports two data centers, the Alloy Phase Diagram Data Center and the Phase Diagrams for Ceramists Data Center, which have become the prime source of evaluated phase information in the U.S. The centers also have developed strong industrial ties, the Alloy Center with the American Society for Metals (ASM) and the Ceramics Center with the American Ceramics Society (ACerS), which ensures that the output is geared to users' needs.

The Alloy Phase Diagram Center is the focal point of the NBS/ASM joint program to evaluate all alloy phase diagrams. Over the last year, the Alloy Center has exerted vigorous technical leadership of the program, especially with respect to setting evaluation standards, developing new and innovative computer graphics for phase diagrams, and editing the Bulletin of Alloy Phase Diagrams.

The Alloy Center, with support of the Office of Naval Research, has been evaluating phase stability data and phase diagrams for all titanium binary alloy systems. Titanium alloys are of major interest for their light weight, high strength, and other properties. A major part of the evaluation has been to extend a thermodynamic optimization computer program so that it can be used interactively and linked to a computer graphics program. Ten titanium systems have been evaluated thus far. In addition to its own merit, the resulting report has been widely circulated to other evaluators as a standard both for quality and format.

Working closely with the Alloy Center, the NBS Center for Applied Mathematics has developed the computer graphics programs mentioned above. First and foremost, the programs can produce publication quality phase diagrams and now generate the diagrams in the Bulletin of Alloy Phase Diagrams. Both binary and ternary systems can be handled. Initial steps have been taken to develop a computer database for phase information. The database will include a graphic and functional representation of the phase diagram data, text, and thermodynamic, crystallographic, and bibliographic data in a searchable computer file. This aspect of the work will be done with the help of ASM research associates working at NBS. 
The Bulletin of Alloy Phase Diagrams, now in its second year of publication, has quickly become a major source of evaluated phase information. Full technical responsibility resides with the Alloy Data Center. The ASM has the publishing responsibitity.

In addition, OSRD supports several other phase data evaluation projects via the OSRD grants programs. The binary systems now covered include copper, vanadium, niobium, the alkali metals, the rare earths, and silver. Evaluations of some of these systems have been already published in the Bulletin. OSRD also interacts with the International Council on Phase Diagrams and works with that group and ASM to find other evaluators and to ensure a 71 evaluations are of high quality. As the number of evaluated systems grows, monographs will be published and the data made available to the computer database.

Ceramics phase diagrams have taken on new importance in recent years as the ceramics industry has grown into innovative areas such as ceramics for high-strength and high-temperature application and metals bonded on ceramic-base materials.

In a joint effort with the American Ceramics Society, the Phase Diagrams for Ceramists (PDFC) Data Center has for many years been involved in the evaluation of ceramics phase diagrams. The fourth volume in the Phase Diagrams for Ceramists Series was completed recently.

The data center and the ACerS are now exploring ways to strengthen the program and meet the increasing demand for more evaluations on more systems. The two major aspects of the proposed enhanced program are to increase support for evaluation and to build a ceramics phase diagrams database. To be ab.le to provide more evaluations each year, the PDFC and the ACerS hope to increase the support for evaluation so that significantly more work can be done. This would also greatiy increase the frequency of publication of volumes in the Phase Diagrams for Ceramists Series. Discussions are presently under way to involve the ceramics industry more closely in this program, and in the upcoming year it is hoped that key support will be forthcoming.

OSRD has been working closely with the PDFC Center to develop a bibliographic database for both their effort and that of other data centers using the NBS central computing facilities. The design stage has been completed, and OSRD has started the programming.

The PDFC phase diagram database is at a much less mature state than the alloy database. However, much of the experience gained by the Alloy Center will be directly applicable to the PDFG effort. Both the design and the programming stages should be greatly shortened by the sharing of experience, a process in which OSRD will be heavily involved. 


\section{Crystallographic Data}

Crystallographic data activities have in recent years reached a very high level of sophistication, which reflects the maturity of the science, the early use of computers by crystallographers, and the growing importance of such data as an identification tool. OSRD-sponsored activities, including the NBS Crystal Data Center, have played an important role in this process, and in the past year several significant milestones were achieved.

The most significant of these has been the release of the NBS Crystal Data Identification File by the NBS Crystal Data Center, This file is being installed as part of the NIH/EPA Chemical Information System (CIS) and will be available for on-line computer use by the beginning of next year. The file contains crystallochemical information on over 60,000 materials and will be of great use both as an analytical tool and as a means of determining what crystallographic work exists for a given species. In addition, OSRD is marketing the data file to national crystallographic data centers, industrial users, and instrument manufacturers.

The second major accomplishment has been the release of crystallographic data evaluation software, called NBS*AIDS80. This program, done jointly with the Joint Committee on Powder Diffraction Standards, has two functions. The first is to analyze published, or soon-to-be-published, data for consistency and accuracy. It is hoped that research scientists and journal editors will find and correct errors before publication, thus improving the quality of published data. The second use is as a tool to create and manipulate large data files in a standard format. The NBS data center is now using these programs to create a master file of crystallographic data.

In addition to the NBS data center, OSRD has supported several other worldwide crystallographic projects which interact strongly with the NBS center. The on-going contract with the Cambridge Crystallographic Centre has this year centered on providing the organic entries to the Crystal Data Identification File. The other major effort has been to process the Cambridge file through NBS*AIDS 80 and create master file entries for the organic substances.

Two other international collaborations were in operation last year. The National Research Council of Canada (Division of Chemistry) continued to provide crystallographic data on metallics and intermetallic substances to the NBS center. Also, an agreement was reached with the crystallographic group at the University of Bonn, West Germany, to provide data for inorganic materials on which full structural determinations have been done. 
Finally, a major effort was started last year to reduce the backlog of literature to be reviewed for inclusion in the data file.

Unfortunately, the NBS personnel reduction has affected the Crystal

Data Center with respect to the data processing and data entry activities.

OSRD and the center are aggressively exploring alternatives for continuing to reduce the backlog.

\section{Diffusion Data}

Diffusion in metals has two major areas of interest in the metals industry: performance and new materials. Diffusion of impurity or alloying constituents plays an important role in determining the performance and useful life of materials in actual use. In recent years, diffusion has also become an important method of altering the surface characteristics of materials, especially to provide high performance properties to a less costly base metal.

The Diffusion in Metals Data Center has been active in providing evaiuated diffusion data to the industrial community and others. The center this past year has completed one major project and has started another.

The Center has finished work on the evaluation of data relating to mass transport and diffusion phenomena in the durability of copper and its alloys, especially multicomponent alioys. These systems are of great interest with respect to understanding and avoiding corrosion problems. This work has been sponsored in part by the International Copper Research Association (INCRA) and will be published next year as Volume 8 of their series on the metallurgy of copper.

In addition, the Data Center has started an automation project which will greatly facilitate their close interaction with the indus. trial community as the primary source of data in all alloy diffusion areas. Using a special OSRD contribution, the Center has contracted with BRS, Inc. to provide on-line bibliographic services for the Center's vast collection of diffusion literature. The file designs have been completed, and the data entry is proceeding. It is hoped in the next year that the first annotated bibliography will be produced. Diffusion research, as pointed out above, is growing in importance and is becoming highly competitive. The access to previous diffusion wark provided by these annotated bibliographies will be of great value in relping U.S. industry to maintain its competitive position. 
PUBLICATIONS IN 1987: The Bulletin of Alloy Phase Diagrams, Volume 2, L. H. Bennett, Editor, American Society for Metals.

Phase Diagrams for Ceramists, Volume IV, Robert S. Roth, Taki Negas, and Lawrence Cook, Editors, American Ceramics Society.

Registration-Identification of Crystalline Materials Based on Lattice and Empirical Formula, J. D. Rodgers and A. D. Mighe1 1, J. Chem. Info. Comp. Sci. 21, 42 (1981).

NBS*AIDS80: A FORTRAN Program for Crystallographic Data Evaluation, A. D. Mighel1, C. R. Hubbard, and J. K. StaTick, NBS Technical Note 1141 (1981). 
J. R. Rumble, Jr., Program Manager

The growth of technology and increase in the availability of computers have given rise to a demand for data dissemination by computerbased methods. This demand has coupled with a need for more efficient and less costly data center operations to produce a major commitment by the Office of Standard Reference Data to automate the internal operations of its data centers and to develop machine-readable numerical data bases for on-line dissemination.

The past year has been highlighted by several important developments. First, OSRD has formulated $\mathrm{plans}$ for creating several important data bases for on-line dissemination. A key factor in the planning process was an extensive survey of the present state of data center automation, which included a two-day workshop involving representatives from all OSRD data centers. Second, substantial progress was made in actually building some of these bases. One, the NBS Crystal Identification Data File, will shortly be available via an on-line network. Much of this progress was supported by special funds provided by the NBS Director's Reserve. Third, OSRD has played a significant part in developing specifications for the new NBS computing facility, especially with respect to the diversified needs of the data centers.

\section{Planning}

This year OSRD made an extensive survey of the state of automation in each of its data centers. This has resulted in a clear overall picture of the capabilities and resources of each center.

An important part of this survey was a two-day workshop held in May. The workshop provided opportunity for data centers to learn about automation activities at other centers. Presentations were made on on-line systems presently available and other developments related to data center automation. About 70 persons attended.

As a result of the survey, OSRD has identified seven generic areas (Table I) which appear most appropriate for developing numerical data bases. Most of these data bases would involve two or more data centers and, in many cases, outside groups. At present, a detailed study is being done of the resources and time required for creation of data bases in each of these areas. Substantial progress has already been made on some.

In addition to building data bases, OSRD has been involved with online dissemination systems. Dr. David Lide has been head of the steering committee of the NIH/EPA Chemical Information System and has worked closely with all involved agencies to increase the effectiveness of that 
system. OSRD has held discussions and meetings with many other groups interested in on-line systems. It is clear that this is a rapidly evolving area and that many changes will be taking place in the next few years.

TABLE I

\begin{tabular}{l}
\hline Proposed OSRD Numerical Data Bases \\
\hline Crystal Data \\
Chemical Thermodynamics \\
Phase Diagrams \\
Atomic Spectra \\
Kinetics of Chemical Reactions \\
Properties of Fluid Mixtures \\
Collision Cross-Sections \\
\hline
\end{tabular}

\section{Progress}

Substantial progress on individual automation projects was achieved during the past year, much of it made possible by a special grant from the NBS Director's Reserve Fund. Six projects resulted directly from this support ranging from logical data base design (Atomic Spectra) to completion of an on-line data base (Crystal Data). These and other automation projects supported by OSRD have been summarized in Table II. More complete descriptions are given in the individual program area narratives.

Progress has also been made in increasing the awareness in data centers of the need for automation to respond to user demands and of OSRD's willingness to help the centers meet such demands.

\section{NBS Computing Facility}

OSRD, and especially the publication group headed by Bettijoyce Molino, has worked closely with the Scientific Computing Division of NBS to upgrade its computer facilities. OSRD's special needs with respect to data base management, large data files, and publications have become an integral part of the NBS plan. This interaction has ensured that the individual data centers will have access to the needed computer resources as the automation effort grows.

\section{The Future}

In spite of budgetary uncertainties, OSRD has an optimistic view of the automation effort. The size of the task is certainly large, but with careful planning and cooperation of other organizations interested in creating on-line data bases, we feel confident we will succeed. 
Some Major OSRD Automation Projects in 1981

Data Center

Atomic Transition

Probabilities

Atomic Energy Levels

Crystal Data

Diffusion in Metals

Chemical Thermodynamics

\section{Fluid Properties}

Alloy Phase Diagrams

Thermal Physics

JILA
Project

Data base logical design

for Atomic Spectra

Dir. Res.

Completion of on-line

NBS Crystal Identification

Data File

Bibliographic data base on

BRS private file system

Master Bibliography on

Thermodynamics

Data Abstracts

Properties on compounds

at $298 \mathrm{~K}$

Reaction Catalog

Thermodynamics and transport properties of fluid mixtures

Computer Graphics for phase diagrams

and $\mathrm{H}_{2} \mathrm{~S}$

Electron collision data
Dir. Res.

ADP

ADP

Dir. Res.

ADP

Dir. Res.

ADP

Dir. Res.

ADP

ADP

ADP 
The following pages provide brief descriptions of the scope and activities of each of the continuing data centers and short-term projects within which the data evaluation and compilation work is carried out. The data centers are listed in alphabetical order by name. The shortterm projects are categorized by the OSRD program area under which they are managed. 


\section{DATA CENTERS}

\section{ALLOY PHASE DIAGRAM DATA CENTER}

Robert Mehrabian, Director

Center for Materials Science, NBS

The Alloy Phase Diagram Data Center collects, evaluates, and distributes phase stability data for metal alloy systems and is the technical coordinator for the NBS-ASM ATloy Phase Diagram Program.

The Center is responsible for the technical content and editing of the Bulletin of Alloy Phase Diagrams, a joint publication with the American Society of Metals. It has rapidly become the prime source of evaluated phase data. Computer graphics software for phase diagrams has been developed and is used to help produce the Bulletin.

A vigorous evaluation program for titanium systems, with support by ONR, is now well in its second year, and 10 titanium binary systems have been evaluated. During this evaluation effort, thermodynamic optimization programs have been enhanced and interfaced with the graphics software.

Work will begin next year on designing and creating a data base of phase information and ancillary data. This will be done in close cooperation with the ASM.

\section{AQUEOUS ELECTROLYTE DATA CENTER}

Bert R. Staples, Director

Center for Chemical Physics, NBS

The Center provides the chemical process and related industries with critically evaluated data on the thermodynamic properties of aqueous electrolyte solutions including activity and osmotic coefficients, excess and partial molar properities of solution, solubilities, and equilibrium constants in solution.

The Center is closely coordinated with the Chemical Thermodynamics Data Center, using its bibliographic resources and providing it with evaluated data on aqueous systems as needed. At the present time, the Center is completing evaluation of data on activity and osmotic coefficients of aqueous electrolyte solutions at $25^{\circ} \mathrm{C}$. The Center also carries out projects for other agencies.

The Aqueous Electrolyte Data Center plans to spend an increasing amount of effort on properties of solutions as a function of temperature. 


\section{ATOMIC COLLISION CROSS SECTION DATA CENTER}

Jean W. Gallagher, Acting Director

Center for Absolute Physical Quantities, NBS

The Center's aim is to compile, evaluate, and disseminate data concerning electron and photon collisions with atoms, simple molecules, ions, and low energy heavy particles. Emphas is is given to electron-collisional excitation and ionization, heavy particle energy transfer, photoionization, photodetachment, and photofragmentation.

Recently the Center has undergone changes which are aimed at defining the scope of the Center so as to be consonant with the most important user needs. As a result, a panel of advisors has identified and recommended a number of data projects involving swarm data in electronegative gases, elastic scattering cross sections for atoms, and the analysis of secondary electron spectra of atoms and molecules. A data index for energy transfer collisions of atoms and molecules was published. A start has been made on establishing an automated numerical data base.

The future thrust of the Center's program will be to complete the efforts initiated and described above. In addition, new projects involving visiting experts to the Center will be sought. Continued effort will be given to the establishment of an automated data file.

\section{ATOMIC ENERGY LEVELS DATA CENTER}

W. C. Martin, Director

Center for Radiation Research, NBS

The Center compiles, evaluates, and disseminates data on energy levels of atoms and atomic ions.

The past effort has been devoted to new compilations of data on iron, cobalt, and silicon. The ultimate goal is to assemble all of the data on the iron group elements into a single volume. Some effort has also been expended toward further automating the data processing within the Center. The next period will be devoted to completing the work detailed above. This work will be done in close cooperation with the Atomic Transition Probabilities Data Center. 


\section{ATOMIC TRANSITION PROBABILITIES DATA CENTER}

Wolfgang L. Wiese, Director

Center for Radiation Research, NBS

The Center's purpose is to compile, evaluate, and disseminate data on atomic transition probabilities and lifetimes of excited levels of atoms and atomic ions.

Considerable effort has been given to updating and revising the data on the transition metals scandium through nickel. As part of the effort, automation techniques have been introduced not only as a means of producing a computer-typeset manuscript but also as a means of establishing an automated data file and retrieval system within the data center. In the coming year the work on the iron group should be completed. Work on updating the data on the light elements will begin. Further effort will be given to data automation.

CINDAS (Center for Information and Numerical Data Analysis and Synthesis)

C. Y. Ho, Director

Purdue University

West Lafayette, Indiana

This is a large data center which receives support from a number of sources. It compiles and evaluates data on transport properties, heat capacities, thermal expansion, and optical, electronic, and electrical properties for a wide range of substances. For OSRD, CINDAS has been involved in the compilation and evaluation of data on thermal conductivity and electrical resistivity of metals and alloys and the thermal conductivity, viscosity, and heat capacities of fluids.

A monograph has been published on the thermal conductivity of a number of alloys. A companion volume on the electrical resistivities of the same alloys and the elements which compose them is in preparation, as is a report on the thermoelectric power of the same metals and alloys.

Work on the electrical resistivity of selected additional metals is expected to be completed in the future, and some work on metallurgically important melts is being considered. 


\section{CHEMICAL KINETICS DATA CENTER}

R. F. Hampson, Director

Center for Chemical Physics, NBS

The Center provides for the compilation, evaluation, and dissemination of chemical kinetic parametric data in support of industrial productivity and environmental integrity. It also develops and improves models or algorithms for the extension and prediction of kinetic parameters.

A number of items are in varying stages of completion. A series of tables on rate constants for chemical combustion reactions has been prepared and will be published during the next year. A table of rate data for reactions of sulfur compounds is being reviewed for publication. An update of data sheets by the CODATA Task Group on Chemical Kirietics has been completed and is slated for formal publication.

Plans for enlarging the scope of the data center to include solution kinetics will be given priority in the coming year. The automation of kinetic data and the methods for developing such a file are to be given a high priority.

\section{CHEMICAL THERMODYNAMICS DATA CENTER}

David Garvin, Director

Center for Chemical Physics, NBS

The Center provides the chemical process and related industries with critically evaluated thermodynamically compatible data which can be used to establish the equilibrium constants and heats of reaction for important chemical reactions. It provides data describing the change in the chemical properties of substances with changes in temperature and at phase-transition points, as well as bibliographic reference services on thermochemistry. In particular, the Center provides enthalpies and Gibbs energies of formation, entropies and $C p$ in the standard state at $298.15 \mathrm{~K}$ and $1 \mathrm{~atm}$. ; enthalpies of formation at $0 \mathrm{~K}$ for inorganic substances and simple organic substances; transition properties; and thermal functions.

The Center is organized into three parts: one maintains and updates the Center's data and bibliographic files and provides input to the Bulletin of Chemical Thermodynamics; one evaluates, estimates, and predicts data; and one develops and provides automated services for record and file input, search and storage, data evaluation, and output.

The Center has recently completed the NBS Tech Note 270 series with the publication of Tech Note 270-8. A combined volume containing 26,000 property values covering 14,300 substances is in preparation. A reaction catalog is being prepared which will serve as documentation to the series as wel1 as input to an automated system which will supplant the previously used manual processes. It also carries out projects for other agencies. 
The Center, which has its own mini-computer, is in the process of converting from a system using mechanical storage of computer-generated records to fully automated operations. The fully automated mode of operation will enabie the Center to participate in a program under which data centers in various countries can cooperate to produce internationally agreed-upon tables.

CRYSTAL DATA CENTER

A. D. Mighe11, Director

Center for Materials Science, NBS

The Crystal Data Center is concerned with crystallochemical data that are required for the identification and characterization of solid state materials. To facilitate the collection, evaluation, and dissemination of these data, a master Crystal Data File is being created, and a fully automated data center wirl be based on this file.

The data center has recently completed a number of projects associated with these goals including the NBS Crystal Data Identification File with data on about 60,000 materiais and a computer program for the evaluation of crystallographic data which has been released to the crystallographic community. The NBS Crystal Data ID File will soon be distributed by the on-7ine NIH/EPA Chemical Information System. It wi]l be updated in the coming year and new data obtained from the literature and from alijed data centers in England, West Germany, and Canada.

Two other important projects, lattice registration and symmetry evaluation, have been started. Lattice registration will aid both in helping to recognize if information on a particular compound is already in the file and in amaigamating related entries. Symmetry evaluation will greatly enhance the data quality.

\section{DIFFUSION IN METALS DATA CENTER}

John Marning, Director

Center for Materials Science, NBS

The Diffusion in Metals Datu Center is concerned with data on diffusion rates and mass transport in metals and their alloys.

The Center has recentily completed a second wolune of wincuify evaluated data dealing with diffusion in copper alloy systems. This work was done under a cooperative agreement with the International Copper Research Association (INCRA) and will be published as part of the INCRA series on the Metallurgy of Copper. It will be a companion to an earlier volume concerned with a different group of copper alloys. 
The data center has also begun an intensive effort to automate. The large data base on diffusion literature is being entered onto an on-line system, which will be able to create, maintain, update, and retrieve the information as needed. Specialized bibliographies on selected diffusion topics will be prepared as the data are entered into the system.

\section{FLUID MIXTURES DATA CENTER}

Neil 01 ien, Director

Center for Chemical Engineering, NBS

The Center is organized to compile and evaluate data on the thermodynamic and transport properties of fluids and fluid mixtures. These properties include formulations for the density and other thermodynamic properties of pure fluids, the viscosity and thermal conductivity of pure fluids, and the same properties for fluid mixtures. The Center is also involved with the development of techniques to predict transport properties of pure fluids from thermodynamic and molecular data, to predict properties of mixtures from the properties of pure fluids, and to interpolate and extrapolate data for properties over a range of temperature, pressure, and--in the case of mixtures--relative concentrations.

At the present time emphasis is on developing thermodynamic formulations for ethylene and for carbon monoxide and for the properties of hydrocarbons. In addition, a monograph is being prepared which will give the density, thermodynamic properties, and transport properties for several fluids over a range of temperatures and pressures using one set of equations with different sets of coefficients for each fluid. Such a format should be particularly easy to program and use on computers, and information for use of the formulations on computers is also being prepared.

With respect to mixtures, the data for the mixture methane-nitrogen, both of which are important components of natural gas, are being compiled and evaluated. The resulting evaluated data base will be used to test the suitability of various types of prediction techniques.

In the past the Center has focused exclusively on light hydrocarbons and cryogenic fluids. It expects to expand its scope of coverage to a wider range of fluids in the future. 


\section{FUNDAMENTAL CONSTANTS DATA CENTER}

Barry N. Taylor, Director

Center for Absolute Physical Quantities, NBS

The Center provides a centralized source of information on the fundamental physical constants and on closely related precision measurements. The Center participates in the periodic development of sets of "best" or recommended values of the fundamental physical constants by means of least-squares adjustments. The self-consistent best values of the constants resulting from an adjustment are required for computational purposes and often are the basis for other data compilations.

A new "least-squares adjustment" should be completed by the end of 1981. The resulting set of recommended values should be adopted for international use by CODATA in early 1982.

\section{ION ENERGETICS DATA CENTER}

Sharon G. Lias, Director

Center for Chemical Physics, NBS

The Center collects, evaluates, and disseminates data pertaining to the thermochemistry of ions. This includes such parameters as ionization potentials, appearance potentials, equilibrium constants, and--ultimately-kinetic rate constants.

The past year has seen the culmination of an effort to collect and compile all of the ionization and appearance-potential data which appeared in the literature in the period 1971-1981. This collection is now being prepared for publication. In the process, many innovations were introduced in automated-data-file handling and computer typesetting routines.

In the coming year, and in addition to the publication of the compilation referred to above, the Center will pursue the complete automation of its data file. It will initiate the evaluation of the data compiled in terms of ionic heats of formation. 


\section{JANAF THERMOCHEMICAL TABLES}

Malcolm W. Chase, Jr., Director

Dow Chemical Company

Midland, Michigan

The JANAF Thermochemical Tables Center covers the thermodynamic properties for the crystal, liquid, and ideal gas state over a wide temperature range. Properties covered are heat capacity, entropy, Gibbs energy function, enthalpy, enthalpy of formation, Gibbs energy of formation, and the logarithm of the equilibrium constant for formation of each compound from the elements in their standard reference states.

Published tabulations involve 35 elements and their compounds. The 35 elements are $\mathrm{H}, \mathrm{Li}, \mathrm{Be}, \mathrm{B}, \mathrm{C}, \mathrm{N}, \mathrm{O}, \mathrm{F}, \mathrm{Na}, \mathrm{Mg}, \mathrm{A} 7, \mathrm{Si}, \mathrm{P}, \mathrm{S}, \mathrm{Cl}, \mathrm{K}, \mathrm{Ca}$, $\mathrm{Ti}, \mathrm{V}, \mathrm{Cr}, \mathrm{Fe}, \mathrm{Co}, \mathrm{Cu}, \mathrm{Br}, \mathrm{Sr}, \mathrm{Zr}, \mathrm{Nb}, \mathrm{Mo}, \mathrm{I}, \mathrm{Cs}, \mathrm{Ba}, \mathrm{Ta}, \mathrm{W}, \mathrm{Hg}$, and $\mathrm{Pb}$.

The Center also generates specified tables of thermodynamic properties, literature surveys, and various automated outputs, largely in connection with the development of an international system for producing chemical thermodynamic data.

\section{MOLECULAR SPECTRA DATA CENTER}

Frank J. Lovas, Director

Center for Chemical Physics, NBS

The Center provides for the collection, evaluation, and dissemination of molecular spectral frequencies and other molecular constants. These are designed to aid in the analysis and identification of compounds and to permit assignment of a wide range of molecular properties. One phase of the Center's work emphasizes microwave spectra of interstellar molecules.

The past year has witnessed the completion of $\mathrm{N}_{2} \mathrm{O}$ absorption spectra for use in calibrating tunable laser spectrometers in regions from 522 to $657 \mathrm{~cm}^{-1}$ and 1115 to $1350 \mathrm{~cm}^{-1}$. Additional1y, microwave spectra for ethanol and propionitrile from 1 to $300 \mathrm{GHz}$ have also been compiled for publication. Other molecules of interest, such as methane, are also being reviewed. Plans are under way to prepare infrared calibration tables on the molecule OCS after the data are carefully checked against a new set of highly accurate measurements. In the microwave region, two compilations of 1 ine spectra will be produced as updates to previously published molecular species. The data will be automated for easy retrieval. 


\section{MOLTEN SALTS DATA CENTER}

George J. Janz, Director

Rensselaer Polytechnic Institute

Troy, New York

The Center's goals are to compile, evaluate, and disseminate physical properties data on selected molten salts. In the past year the Center published data applicable for energy storage systems and also issued a series of standard values of various properties for molten $\mathrm{KNO}_{3}$ and $\mathrm{NaCl}$. Some attention is also being given the automation of the data assembled into a retrievable data base.

Future efforts will be concerned with the extension of the evaluative process to new properties of molten salts, such as diffusion. Also, computerized techniques for data handling and manuscript publication will be pursued.

\section{NATIONAL CENTER FOR THE THERMODYNAMIC DATA OF MINERALS}

John L. Haas, Jr., Director

U.S. Geological Survey

Reston, Virginia

The Center compiles, indexes, and evaluates data on the thermodynamic and thermophysical properties of minerals, their synthetic analogs, and geologic materials. These data are important for geochemical purposes and useful industrially in the fields of metallurgy and the synthesis and production of inorganic chemicals.

In particular, the Center develops critically evaluated thermodynamic data for naturally occurring solid phases or their chemical end members. Properties considered are heat capacity, entropy, enthalpy, Gibbs energy, enthalpy and Gibbs energy of formation, molar volume, molar compressibility, and molar expansivity, all as functions of temperature, and phase diagrams of systems containing mineral phases. The Center cooperates closely with the Chemical Thermodynamics Data Center and the JANAF Thermochemical Tables Project.

Some recent activities have centered about properties of geologi: structures suggested as burial sites for high-level nuclear wastes. 


\section{PHASE DIAGRAMS FOR CERAMISTS DATA CENTER}

L. P. Cook, Director

Center for Materials Science, NBS

The Phase Diagrams for Ceramists (PDFC) Data Center has two primary goals: the regular publication of evaluated phase stability information for inorganic nonmetallic systems and the development of a computersearchable "Phase Diagrams for Ceramists" data base.

The PDFC Center has published jointly with the American Ceramic Society the series "Phase Diagrams for Ceramists." Volume 4, the first since 1975, contains 590 diagrams for metal-oxygen and metal-oxide systems as well as oxygen-containing radicals. Volume 5 will contain 650 diagrams of molten salts, sulfides, and oxynitride systems. Volume 4 will be available in late 1981, and volume 5 will follow next year. Evaluation work for volumes 6 and 7 has started.

A comprehensive long-range plan for development of the "Phase Diagrams for Ceramists" data base, in collaboration with the American Ceramic Society, has been developed. The main features of the plan are increased automation involving all: aspects of the project and increased evaluation effort.

\section{PHOTON AND CHARGED PARTICLE DATA CENTER}

\section{J. Berger, Director}

Center for Radiation Research, NBS

The Center compiles, evaluates, and disseminates data on the interaction of ionizing radiation with matter. The data on photons and charged particles include single-scattering cross sections and transport data pertaining to penetration of radiation through bulk matter.

The past year has seen a reorganization in which two data centers, the X-ray and Ionizing Radiation Data Center and the Photonuclear Data Center, were combined to form the present Center. In making this change, certain new directions were undertaken in the area of charged particle interactions. The traditional work of the two centers which were combined will be continued as appropriate. Thus, a review on high-energy photon cross sections in elements $Z=1-100$ was completed and published. Work on mass attenuation coefficients is continuing. Some effort has been expended in automating the photon cross section data into a retrievable file.

The next period will see a continuation of the work on photon cross sections, as well as initiation of work on the stopping powers and ranges of protons. The Photonuclear Data Index will be updated and distributed to its interested community. The computerization of the photon cross section data will be continued. A bibliographic file will also be constructed for automated search and retrieval. 


\section{RADIATION CHEMISTRY DATA CENTER}

Alberta B. Ross, Director

Radiation Laboratory, University of Notre Dame

Notre Dame, Indiana

The Center's purpose is to compile, evaluate, and disseminate rate parameters and related data on chemical reactions initiated by the interaction of ionizing and photon radiation with matter. Emphasis is placed on those reactions occurring in aqueous and liquid media.

Over the past year, the Center has produced several manuscripts for publication in both the NSRDS-NBS series and the JPCRD. It has also prepared bibliographic material for inclusion, on an annual basis, in the Journal of Radiation Physics and Chemistry. Other bibliographic activities involve their publication in the Biweekly List of Papers on Radiation Chemistry and Photochemistry and the Annual Cumulation of the Biweekly List. They have also devoted time to the improvement of their automated files, where some data are now internally available on-line.

The next period will be devoted to further improvements in their automated data files.

\section{THERMODYNAMICS RESEARCH CENTER}

K. R. Hal1, Director

Texas A \& M University

College Station, Texas

The Center provides the chemical process and related industries with critically evaluated data on a wide variety of thermodynamic and thermophysical properties of organic compounds. These include thermodynamic properties of organic materials, condensed-phase properties, transition points and properties, density and vapor pressure of 1iquids, and ideal gas and real gas properties.

The Center maintains an extensive data file and contributes a major section to the Bulletin of Chemical Thermodynamics. It is currently involved with the preparation of chemical thermodynamic tables giving formation properties over a range of temperatures for a set of organic, oxygen-containing substances. Work is also proceeding on building an automated data file at Texas $A$ \& $M$ and introducing data on organic compounds into the Chemical Information System (CIS). A parallel project is carried out for the American Petroleum Institute which develops evaluated data in hydrocarbons and other substances important in petroleum refining. 


\section{THERMODYNAMIC RESEARCH LABORATORY}

Buford D. Smith, Director

Washington University

St. Louis, Missouri

This laboratory compiles and evaluates data on the vapor-liquid equilibrium, excess enthalpy, and excess volume of binary subcritical fluid mixtures and data on the vapor pressures, enthalpies of vaporization, saturated-liquid densities, and virial coefficients of pure fluids which are components of the mixtures. The laboratory is funded jointly by industry and the Office of Standard Reference Data (OSRD). It covers a wide range of fluid mixtures, but its work for OSRD is focused on hydrocarbon-hydrocarbon systems with carbon numbers $C_{\hat{2}}-C_{8}$ and mixtures of hydrocarbons with aliphatic alcohols.

Reports are currently being prepared for the systems benzenecyclohexane, benzene-hexane, and cyclohexane-hexane. These systems are used for calibration purposes, and there is a large amount of data, covering a range of compositions and temperatures, available for them. A report is also being prepared covering the theoretical techniques used in evaluating the vapor-liquid equilibrium data and various problems that have been met in the course of the analysis.

A series of reports on hydrocarbon-hydrocarbon systems and hydrocarbonaliphatic-alcohol systems is expected in the future. 


\section{PROJECTS (Energy and Environmental)}

\section{CRITICAL COMPILATION OF MASS SPECTRAL DATA}

Martin G. Robiette

Mass Spectral Data Centre, UK

Source of Support: NBS

The project compiles, evaluates, and enters mass spectral data into the Chemical Information System (CIS). The data are collected from the open literature and other sources, private and public. Their quality is assessed through the application of a quality index algorithm. Those data which are considered of high quality are submitted for entry into the CIS and are also reproduced in hard-copy form through supplements to NSRDS-NBS 63, the NIH-EPA Mass Spectral Data Base.

\section{CRITICAL EVALUATION OF HIGH TEMPERATURE KINETIC DATA}

\section{N. Cohen}

Aerospace Corporation

Source of Support: DOD and NBS

This project compiles and disseminates evaluated data sheets describing the high-temperature kinetics of selected chemical reactions found to occur in rockets and jets.

After spending considerable time working on the data sheet format, progress has been made in extending the number of data sheets produced. Over the past year, 15 data sheets were prepared. They include the more basic combustion-oriented elementary reactions of hydrogen and oxygen. The next period will see an examination of solid propellant systems $(A] / 0, B / 0$, and $B / F)$, some $\mathrm{OH}-a l$ kane and $\mathrm{OH}-\mathrm{alk}$ kene reactions, and some hydrazine reactions. 
EVALUATION OF MECHANICAL, THERMAL, AND ELECTRICAL PROPERTY DATA OF BASALT

C. Y. Ho

Center for Information and Numerical Data Analys is and Synthes is (CINDAS), Purdue University

Source of Support: DOE-Battelle

This project is part of a coordinated effort to produce evaluated data on selected physical properties of basalt. Basalt is being considered as a candidate for the burial of high-level nuclear wastes. This effort will deal with mechanical properties such as static and dynamic elastic properties, hardness, strength, and creep; thermal properties such as thermal conductivity and thermal expansion; and electrical properties such as electrical resistivity. The entire range of temperature and pressure will be examined. The data will be published in proper form for use by burial site designers.

EVALUATION OF THERMODYNAMIC AND THERMOCHEMICAL DATA FOR THE COMPONENTS OF BASALT

John L. Haas, Jr.

National Center for Thermodynamic Data of Minerals

U.S. Geological Survey

Source of Support: DOE-Battelle

This project is part of a coordinated effort to produce evaluated data on selected physical properties of basalt. Basalt is being considered as a candidate for the burial of high-level nuclear wastes. Specifically, this work will assemble and evaluate the chemical and mineralogical properties including heat capacity, enthalpy, and entropy of basalt components; review the kinetics of chemical change within basalt and its components; and produce equations of state for the formation and change of these components. The evaluated data will be tested in models for predicting the chemical reactions that may occur and for the calculation of the production or consumption of heat associated with such reactions. These in turn will be used to determine the integrity of the medium when in contact with the buried waste. The data will be published in convenient form for use by burial site designers. 


\section{WATER SOLUBILITY AND RELATED PARAMETERS OF COAL DERIVED COMPOUNDS}

Sujit Banerjee

Syracuse Research Corporation

Source of Support: DOE and NSF

Data on the water solubility of polynuclear aromatic and heteroaromatic compounds derived from coal will be compiled and evaluated. The evaluated data will be checked against selected theoretical models to establish a relationship between experimental solubility values and those calculated from chemical structure parameters. A manuscript will be prepared containing the selected data.

A CRITICAL COMPILATION OF THE SOLUBILITY OF OXYGEN, OZONE, AND NITROGEN IN LIQUTDS

Rubin Battino

Wright State University

Source of Support: NSF

This project involves the preparation and critical compilation of data sheets giving the solubility of oxygen, ozone, and nitrogen in liquids, including liquid mixtures, over a range of pressure. These data will be evaluated, and smoothed recommended values will be produced. This project is nearing completion, and a final manuscript containing the results will be produced during the next year.

SOLUBILITY OF THE SPARINGLY SOLUBLE SALTS OF ZINC, CADMIUM, AND MERCURY IN WATER AND AQUEOUS SALT SYSTEMS

H. Lawrence Clever

Emory University

Source of Support: NSF

A manuscript containing evaluated data on the solubility of zinc, cadmium, and mercury salts in water and aqueous electrolyte solutions will be written. The anions of interest include the halides, sulfides, sulfates, phosphates, and carbonates at a 11 temperatures and pressures. In addition, an annotated bibliography on all the other anions for which data are available will be assembled. 
Raymond L. Kelly

Spectroscopic Data Center, Naval Postgraduate School

Source of Support: NSF

The project has been established to permit the completion of a compilation of atomic spectral lines with wavelengths below 2000 Angstroms. In the past year, tables containing the wavelength, intensity, and classification for all lines observed in solar and terrestrial sources as reported in the literature have been assembled. Data for 26 elements were revised and updated. The next period should see the completion of the effort through zinc and preparation of an initial publication.

CRITICAL EVALUATION OF CHEMICAL KINETIC DATA FOR METASTABLE ELECTRONICALLY EXCITED SPECIES

K. Schofield

ChemData Corporation

Source of Support: DOE

A critical evaluation will be performed on the available chemical kinetic rate data for the gas phase reactions of selected electronically excited species. In a11, 19 species will be reviewed. They include excited states for $\mathrm{NH}, \mathrm{O}_{2}, \mathrm{CN}, \mathrm{C}_{2}, \mathrm{CH}, \mathrm{NO}, \mathrm{I}$, and $\mathrm{N}_{2}$. The data will be presented in a format similar to a previous publication on the subject and will also indicate where additional data are required.

A CRITICAL COMPILATION OF PROPERTIES DATA ON NONAQUEOUS SOLVENTS IMPORTANT TO BATTERY DEVELOPMENT

R. P. T. Tomkins

New Jersey Institute of Technology

Source of Support: DOE

A critical compilation of data on the transport and thermodynamic properties, kinetics, surface and structural aspects, and performance data will be produced. Compounds examined will include those of lithium, calcium, and sodium in electrolytes such as sodium polysulfides, antimony trichloride, sulfur dioxide, thionyl chloride, and selected organic solvents. The data will be recorded both at ambient and high temperature. The evaluated data will be prepared in a form suitable for publication. 
DATA FOR FLUE-GAS SCRUBBERS

David Garvin

Chemical Thermodynamics Data Center, NBS

Source of Support: DOE

Efficient design of flue-gas scrubbers requires an extensive knowledge of the thermochemistry of the interactions of the various oxidation products of sulfur with solutions in water of Time, calcium carbonate, doiomite, etc., over a range of temperatures and $\mathrm{pH}$ values. Some of the needed data are available in the Center's files; other data will be compiled and evaluated or estimated.

\section{HEATING VALUES OF HYDROCARBONS}

\section{G. Armstrong}

Chemical Thermodynamics Data Center, NBS

Source of Support: GIIGNL

The heating values of $C_{2}$ through $C_{5}$ hydrocarbons are being evaluated over a range of conditions to provide authoritative data for the valuation of natural gas and 1 iquefied natural gas on an international basis.

\section{PROPERTIES OF ELECTROLYTE SOLUTIONS}

Bert Staples

Aqueous Electrolyte Data Center, NBS Source of Support: DIPPR

Design-oriented calculation methods are being developed for electrokyte systems, and critically evaluated data are being compiled for specific systems. The purpose is to provide a "data book" of thermodynamic data and recommended procedures for calculation. Three classes of problems are under consideration: vapor-liquid-equilibrium calculations for industrially important systems such as $\mathrm{SO}_{2}-\mathrm{H}_{2} \mathrm{O}$ and $\mathrm{CO}_{2}-\mathrm{H}_{2} \mathrm{O}$; prediction of precipitation for heavy metal systems such as hydroxide precipitation of chromium; prediction of gypsum precipitation under varying conditions of concentration, temperature, ionic strength, and pressure. 
PREPARATION OF POURBAIX DIAGRAMS FOR SELECTED SYSTEMS

Marcel Pourbaix

Belgian Center for Corrosion Study

Brussels, Belgium

Source of Support: DOE

A report will be prepared on the influence of temperature and pressure on the chemical and electrochemical equilibria of the systems $0, \mathrm{H}, \mathrm{Fe}$, $\mathrm{O}-\mathrm{H}, \mathrm{O}-\mathrm{Fe}, \mathrm{H}-\mathrm{Fe}, \mathrm{O}-\mathrm{H}-\mathrm{Fe}, \mathrm{C}, \mathrm{O}-\mathrm{C}, \mathrm{C}-\mathrm{Fe}, \mathrm{O}-\mathrm{C}-\mathrm{Fe}$. This project is part of a larger program on chemical equilibria involved in corrosion processes.

THERMODYNAMICS IN HIGH-TEMPERATURE PROCESSES

D. L. Hildenbrand with L. Brewer, G. M. Rosenblatt, D. Cubicciotti SRI International

Menlo Park, California

Source of Support: DOE

A report will be prepared on the vaporization behavior of 50 binary oxide systems including vapor composition and thermodynamic properties of condensed and gaseous oxides. These oxides are important for a wide range of industrial uses including metallurgy, high-temperature applications of construction materials, batteries, nuclear reactors, and glass making.

PROPERTIES OF ALKALI METAL VAPORS

W. C. Stwalley

University of Iowa

Iowa City, Iowa

Source of Support: NSF

A report will be prepared on the dissociation energies, potential energy curves, and other molecular constants of alkali metal molecules, and thermodynamic properties of alkali metal vapors. These data are necessary in the design and construction of lasers. 
PROPERTIES OF POLAR FLUIDS

L. Haar, J. M. H. Levelt Sengers

Center for Chemical Engineering, NBS

Source of Support: NBS

This project has been focused on pure fluids in the past. It is currently finishing a major effort on water and steam. This effort has involved substantial improvements in the techniques of developing formuTations to provide the density and thermodynamic properties of a fluid over a wide range of temperature and pressure. The formulation developed has been extensively documented in terms of its fit to experimental data in accordance with the requirements of the International Association for the Properties of Steam (IAPS) and is being considered by that organization as a possible replacement for its IFC 1968 Formulation for Scientific and General Use. The project has also developed a scaling-law formulation for steam in the critical region and is working on the joining of the analytic and scaling formulations to provide a single formulation. Work is also proceeding on developing a formulation for the thermodynamic properties of $\mathrm{H}_{2} \mathrm{~S}$. The project is currently moving into the study of mixtures containing a polar component.

\section{THERMOPHYSICAL PROPERTIES DATA FOR FLUIDS}

\section{J. V. Sengers}

University of Maryland, College Park, Maryland Source of Support: NSF

This project is concerned with the development of comprehensive formulations for the thermodynamic and transport properties of fluids. This includes formulations providing an accurate description of the behavior in the critical regions. The techniques are being applied to the properties of water and steam as part of an international effort under the IAPS.

\section{THERMODYNAMIC PROPERTIES OF HYDROCARBONS}

Neil 01 ien

Fluid Mixtures Data Center

Source of Support: GRI

This project will provide reference data on the thermodynamic properties of propane, butane, and isobutane over a range of temperatures and pressures. 
TRANSPORT PROPERTIES OF HYDROCARBONS

Neil 01 ien

Fluid Mixtures Data Center

Source of Support: DOE

Evaluated transport property data prepared by the American Petroleum Institute (API) are being refitted to allow inclusion in TRAPP, a computerized system which provides the user with transport property data for a number of simple fluids.

\section{THERMODYNAMIC PROPERTIES OF ISOBUTANE}

J. M. H. Levelt Sengers

Polar Fluids Project

Source of Support: DOE

This project will provide a formulation for the properties of isobutane which will cover the needs of engineers using isobutane as a working fluid in extracting energy from geothermal sources. (The range of coverage differs from that of the GRI project.)

THERMODYNAMIC PROPERTIES OF AIR AND ITS COMPONENTS

R. B. Stewart, R. T. Jacobsen

University of Idaho, Moscow, Idaho

Source of Support: DOE

Formulations are being prepared for air, oxygen, nitrogen, and argon. A11 of these fluids are of industrial importance. The same equation will be used for all fluids. The results for the pure fluids will be used by the Fluid Properties Data Center. The formulations will also be used to study the feasibility of using properties of single fluids to predict the properties of mixtures.

\section{THERMODYNAMIC PROPERTIES OF ETHYLENE}

R. T. Jacobsen, R. B. Stewart

University of Idaho, Moscow, Idaho

Source of Support: DOE

A report will be prepared on the critical evaluation of data for ethylene and the development of a formulation for the density and thermodynamic properties of ethylene over a wide range of temperature and pressure. The work is coordinated closely with similar work at the Fluid Mixtures Data Center. 


\section{THERMODYNAMIC PROPERTIES OF KETONES}

\section{Buford D. Smith}

Thermodynamics Research Laboratory Washington University

St. Louis, Missouri

Source of Support: NSF

A comprehensive compilation and evaluation will be made on selected thermodynamic properties of ketones. The ketones studied are components in binary systems for which thermodynamic data exist. The properties to be evaluated are those needed in the evaluation and prediction of mixture data. The work will be closely coordinated with the studies of mixture properties being carried out at the same Center.

\section{DIPPR DATA PROJECTS}

\section{AIChE}

New York, New York

Source of Support: NBS, Industry

DIPPR supports a number of data compilation, evaluation, and prediction projects with cooperative funding from industry and Government. In accordance with an agreement between NBS and AIChE, the parent organization of DIPPR, DIPPR and NBS will cooperate in a variety of ways in the production of critically evaluated data for industry. NBS is providing funds to DIPPR which are being used to support a data prediction manual and a project on electrolyte phase equilibria.

\section{EQUILIBRIUM AND TRANSPORT PROPERTIES OF NOBLE GASES AND THEIR MIXTURES AT} LOW DENSITIES

J. Kestin, E. A. Mason

Brown University

Providence, Rhode Island

Source of Support: NSF

This project is designed to exploit recently developed techniques to obtain intermolecular potentials from experimental data to provide definitive data on the thermodynamic and transport properties of noble gases and their mixtures. 
PROJECTS (Materials Properties)

CATION-NITROGEN DISTANCE IN NITRIDES OF CRYSTALLINE COMPOUNDS

W. H. Baur

University of Illinois - Chicago Circle

Source of Support: DOE

This project will review and evaluate cation radij for crystalline nitride compounds. It has been found for many crystalline materials that, for a given anion, the cation radius remains the same despite differences in bond types and other structural changes. This has led to useful results, based on an assumption of the additive nature of these radii. However, the cation radii do change for different anions. The cation radij for nitride systems will be reviewed, and an evaluated set of radii will be generated. The nitride compounds have been chosen because of their significance in ceramic materials.

\section{CRYSTALLOGRAPHIC DATA FOR METALS}

L. D. Calvert

National Research Council

Ottawa, Ontario, Canada

Source of Support: NBS

For the past several years, this project has provided the NBS Crystal Data Center with crystallographic structural data for metallic and intermetallic materials. This year the literature covered is that surveyed in the 1979 Structural Reports. The data are incorporated into the NBS Crystal Data ID File.

REFERENCE DATA ON THE REFRACTIVE INDEX OF SELECTED OPTICAL MATERIALS

H. H. Li

\section{CINDAS}

Purdue University

West Lafayette, Indiana

Source of Support: DOE

This project will produce recommended reference values for the refractive index of optically important materials, especially those which are serious candidates for use in high-power laser windows and for solar energy applications. The materials to be surveyed include cadmium and zinc sulfides, selenides and tellurides, and certain oxides and halides. All published work on this subject will be reviewed and the data evaluated. 


\section{CRYSTALLOGRAPHIC DATA FOR ORGANIC MATERIALS}

0. Kennard

Cambridge Crystallographic Data Centre

Cambridge, England

Source of Support: NBS

The Cambridge Crystallographic Data Centre has had a continuing collaboration with the NBS Crystal Data Center. The Cambridge Centre supplied two key sets of information: (1) numerical crystallographic data and references for organic and organo-metallic materials, and (2) actual copies of all published crystallographic research on inorganic materials.

During the past year, the Cambridge Centre has also provided the information needed for the organic material section of the NBS Crystal Data ID File, which is soon to be distributed on-line.

In the coming year, one key project will be completed and another started. Cambridge will supply the organic entries for the NBS Master Data File in the appropriate format, a major step forward in creating this important file. In addition, production of the next volume of Crystal Data will begin. This volume will contain data on over 20,000 organic materials.

\section{OSRD BINARY PHASE DIAGRAM EVALUATION PROJECTS}

Silver Alloys

John H. Perepezki

University of Wisconsin - Madison

Source of Support: NSF

Rare Earth Alloys

K. A. Gschneidner

Iowa State University

Ames, Iowa

Source of Support: DOE

Copper Alloys

D. E. Laughl in

Carnegie-Mellon University

Pittsburgh, Pennsylvania

Source of Support: DOE 
Vanadium and Niobium Alloys

J. F. Smith

Ames Laboratory of DOE

Iowa State University

Ames, Iowa

Source of Support: DOE

Titanium Alloys

R. Mehrabian

National Bureau of Standards

Source of Support: ONR

These evaluation projects are a major part of the National Bureau of Standards-American Society of Metals (ASM) joint program to provide reliable phase stability information to the U.S. materials community. The format of all projects is the same. For each binary system a recommended phase diagram will be produced with explanatory text including evaluation of available experimental, crystallographic, and thermodynamic data. The outputs will be published first in the Bulletin of Alloy Phase Diagrams and, as larger numbers of systems are completed, in a series of monographs published by ASM.

The titanium, vanadium, and silver projects are now in their second year, and a substantial number of systems have been evaluated. 


\section{PUBLICATIONS IN 1981}

\section{Journal of Physical and Chemical Reference Data, Volume 10}

Evaluated Activity and Osmotic Coefficients for Aqueous Solutions: Bi-Univalent Compounds of Zinc, Cadmium, and Ethylene Bis (Trimethy?ammonium) Chloride and Iodide Robert N. Goldberg

Tables of the Dynamic and Kinematic Viscosity of Aqueous KCl Solutions in the Temperature Range 25-150 ${ }^{\circ} \mathrm{C}$ and the Pressure Range 0.1-35 MPa Joseph Kestin, H. Ezzat Khalifa, and Robert J. Correia

Tables of the Dynamic and Kinematic Viscosity of Aqueous $\mathrm{NaCl}$ Solutions in the Temperature Range 20-150 ${ }^{\circ} \mathrm{C}$ and the Pressure Range 0.1-35 MPa Joseph Kestin, H. Ezzat Khalifa, and Robert J. Correia

Heat Capacity and Other Thermodynamic Properties of Linear Macromolecules. I. Selenium. Umesh Gaur, Hua-Cheng Shu, Aspa Mehta, and Bernhard Wunderlich

Heat Capacity and Other Thermodynamic Properties of Linear Macromolecules.

II. Polyethylene Umesh Gaur and Bernhard Wunderlich

Energy Levels of Sodium, $\mathrm{Na}$ I through $\mathrm{Na} X I$ William C. Martin and Romuald Zalubas

Energy Levels of Nickel, $\mathrm{Ni}$ I through $\mathrm{Ni}$ XXVIII Charles H. Corliss and Jack Sugar

Ion Product of Water Substance, 0-1000 ${ }^{\circ} \mathrm{C}, 1-10,000$ Bars. New International Formulation and Its Background

W. L. Marshall and E. U. Franck

Atomic Transition Probabilities for Iron, Cobalt, and Nickel: A Critical Data Compilation of Allowed Lines

Jeffrey R. Fuhr, Georgia Martin, Wolfgang L. Wiese, and S. M. Younger

Thermodynamic Tabulations for Selected Phases in the System

$\mathrm{CaO}-\mathrm{Al}_{2} \mathrm{O}_{3}-\mathrm{SiO}_{2}-\mathrm{H}_{2} \mathrm{O}$ at $101.325 \mathrm{kPa}(1 \mathrm{~atm})$ between 273.15 and $1800 \mathrm{~K}$ John L. Haas, Jr., Gilpin R. Robinson, Jr., and Bruce S. Hemingway

Evaluated Activity and 0smotic Coefficients for Aqueous Solutions: Thirty-Six Uni-Bivalent Electrolytes

Robert N. Goldberg 
Activity and Osmotic Coefficients of Aqueous Alkali Metal Nitrites Bert R. Staples

Activity and Osmotic Coefficients of Aqueous Sulfuric Acid at $298.15 \mathrm{~K}$ Bert R. Staples

Rate Constants for the Decay and Reactions of the Lowest Electronically

Excited Singlet State of Molecular Oxygen in Solution

Francis Wilkinson and James C. Brummer

Heat Capacity and Other Derived Thermodynamic Properties of Linear Macromolecules. III. Polyoxides

Umesh Gaur and Bernhard Wunderlich

Heat Capacity and Other Thermodynamic Properties of Linear Macromolecules.

IV. Polypropylene

Umesh Gaur and Bernhard Wunderlich

Tables of $\mathrm{N}_{2} \mathrm{O}$ Absorption Lines for the Calibration of Tunable Infrared

Lasers from $522 \mathrm{~cm}^{-1}$ to $657 \mathrm{~cm}^{-1}$ and from $1115 \mathrm{~cm}^{-1}$ to $1340 \mathrm{~cm}^{-1}$

W. B. 01son, Arthur G. Maki, and Walter J. Lafferty

Microwave Spectra of Molecules of Astrophysical Interest. XX. Methane

I. Ozier, M. C. L. Gerry, and A. G. Robiette

Energy Levels of Cobalt, Co I through Co XXVII Jack Sugar and Charles H. Corliss

A Critical Review of Henry's Law Constants for Chemicals of Environmental Interest

Donald Mackay and Wan Ying Shiu

Evaluated Kinetic Data for High Temperature Reactions. Volume 4.

Homogeneous Gas Phase Reactions of Halogen- and Cyanide-Containing Species

D. L. Baulch, J. Duxbury, S. J. Grant, and D. C. Montague

Journal of Physical and Chemical Reference Data

Cumulative Indexes for Volumes 1 to 10

\section{NSRDS-NBS Series}

Physical Properties Data Compilations Relevant to Energy Storage. IV.

Molten Salts: Data on Additional Single and Multi-Component Salt Systems G. J. Janz and R. P. T. Tomkins NSRDS-NBS 61 - IV 
Physical Properties Data Compilations Relevant to Eriergy Storage. V. Mechanical Properties Data on Alloys for Use in Flywheels

H. M. Ledbetter

NSRDS-NBS 61 - V

Optical Spectra of Nonmetallic Inorganic Transient Species in Aqueous Solution

Gordon L. Hug

NSRDS-NBS 69

Data Publications from Other Publishers

The Bulletin of Alloy Phase Diagrams, Volume 2

L. H. Bennett, Editor

American Society for Metals

The Critical Region Equation of State of Ethylene and the Effect of Small Impurities

J. R. Hastings, J. M. H. Levelt Sengers, and F. W. Balfour

J. Chem. Thermodynamics 12, 1009 (1980)

Phase Diagrams for Ceramists, Volume IV

Robert S. Roth, Taki Negas, and Lawrence Cook, Editors

American Ceramics Society

Registration-Identification of Crystalline Materials Based on Lattice and Empirical Formula

J. R. Rodgers and A. D. Mighel1

J. Chem. Info. Comp. Sci. 21, 42 (1981)

\section{Data Publications in Other NBS Series}

Physical Properties for Rock Salt

Lewis H. Gevantman

NBS Monograph 167

Selected Values of Chemical Thermodynamic Properties: Compounds of Uranium, Protactinium, Thorium, Actinium, and the Alkali Metals

D. D. Wagman, W. H. Evans, V. B. Parker, R. H. Schumm, and

R. L. Nuttall

NBS Technical Note $270-8$

An Equation of State for Fluid Ethylene

R. D. McCarty and R. T. Jacobsen

NBS Technical Note 1045

NBS*AIDS80: A FORTRAN Program for Crystallographic Data Evaluation A. D. Mighe11, C. R. Hubbard, and J. K. Stalick

NBS Technical Note 1141 (1981) 
Data Index for Energy Transfer Collisions of Atoms and Molecules 1970-1979

J. W. Gallagher, Janet Van Blerkom, E. C. Beaty, and J. R. Rumble, Jr. NBS Special Publication 593

Thermodynamic Properties of Miscellaneous Materials

Eugene S. Domalski, William H. Evans, and Thomas L. Jobe, Jr. NBSIR 78-1479

Tables of Experimental Rate Constants for Chemical Reactions Occurring

in Combustion (1971-1977)

Francis Westley

NBSIR 81-2254

Chemical Thermodynamic Data Banks

David Garvin, Vivian B. Parker, and Donald D. Wagman

NBSIR 81-2341

A Report on Thermodynamic Data for Desulfurization Processes

V. B. Parker, B. R. Staples, T. L. Jobe, Jr., and D. Neumann NBSIR $81-2345$

Heating Values of Natural Gas and Its Components George Armstrong and Thomas L. Jobe, Jr. NBSIR 81-

\section{Bibliographies and Indexes from Other Publishers}

Biweekly List of Papers on Radiation Chemistry and Photochemistry, Annual Cumulation with Keyword and Author Indexes, Volume 13, 1980 Radiation Chemistry Data Center

Radiation Laboratory

University of Notre Dame

Natre Dame, IN 46556

Biweekly List of Papers on Radiation Chemistry and Photochemistry, Volume 14, 1981

Radiation Chemistry Data Center

Radiation Laboratory

University of Notre Dame

Notre Dame, IN 46556

Bulletin of Chemical Thermodynamics, Volume 24, 1981

IUPAC Commission on Thermodynamics and Thermochemistry

Robert D. Freeman, Editor 
Bibliographies and Indexes in Other NBS Series

Feasibility Study: Compilation and Evaluation of Properties Data for Basalt, Granite, Tufr, and Shale

L. H. Gevantman

NBSIR $81-2217$

Standard Reference Data Publications, 1964-1980

G. B. Sherwood

NBS Special Publication 612 
PUBLICATIONS SCHEDULED FOR 1982

Journal of Physical and Chemical Reference Data, Volume 11

A Fundamental Equation of States for Heavy Water

P. Hill, R. D. Chris Macmillan, and V. Lee

Energy Levels of Iron, Fe I through Fe XXVI

C. Corliss and J. Sugar

Evaluated Chemical Kinetic Data Sheets for High Temperature Chemical

Reactions

N. Cohen and K. Westberg

Intensities of Microwave Absorption Lines of Carbonyl Sulphide. Tabulation of Peak Absorption Coefficients

Z. Kisiel and D. J. Millen

Heat Capacity and Other Thermodynamic Properties of Linear Macromolecules.

V. Polystyrene

U. Gaur and Bernhard Wunderlich

Volumetric Properties of Aqueous Sodium Chloride Solutions

P. S. Z. Rogers and K. S. Pitzer

JANAF Thermochemical Tables, 1981 Supplement

M. W. Chase et al.

Heat Capacity, Entropies, and Some Phase Transition Properties of Organic Compounds in Liquid and Solid Phases

E. S. Domalski, W. H. Evans, and E. D. Hearing

Molten Salts Data: Diffusion Coefficients in Single and Multi-Component Salt Systems

G. J. Janz and N. B. Bansal

Microwave Spectra of Molecules of Astrophysical Interest. XXI. Ethanol

$\left(\mathrm{C}_{2} \mathrm{H}_{5} \mathrm{OH}\right)$ and Propionitrile $\left(\mathrm{C}_{2} \mathrm{H}_{5} \mathrm{CN}\right)$

Water Molecule Form Factors and Photon Coherent Scattering Cross Sections L. R. M. Morin

Evaluated Kinetic and Photochemical Data for Atmospheric Chemistry, Supplement I.

D. L. Baulch, R. A. Cox, P. J. Crutzen, R. F. Hampson, Jr.,

J. A. Kerr, J. Troe, and R. T. Watson 
Thermophysical Properties of Fluids: Argon, Ethylene, Parahydrogen, Methane, Nitrogen, Nitrogen trifluoride, and Oxygen

B. A. Younglove

Selected Values of Chemical Thermodynamic Properties, 1982 Edition

D. D. Wagman, W. H. Evans, V. B. Parker, R. H. Schumm, I. Halow,

S. M. Bailey, K. L. Churney, and R. L. Nuttall

\section{NSRDS-NBS Series}

Ionization Potential and Appearance Potential Measurements, 1971-1981

R. D. Levin and S. G. Lias

NSRDS-NBS 70

Tables of Rate Constants for Gas Phase Chemical Reactions of Sulfur Compounds (1971-1980)

F. Westley

NSRDS-NBS

\section{Publications in Other NBS Series}

Medical Physics Data Book

T. N. Padikal and S. P. Fivozinsky

NBS Handbook 138

Interactive FORTRAN Program to Calculate Thermophysical Properties of Seven Fluids

B. A. Younglove

NBS Technical Note 1048

\section{Publications from Other Publishers}

Bulletin of Alloy Phase Diagrams, Volumes 2 and 3

L. H. Bennett, Editor

American Society for Metals

Diffusion Rate Data and Mass Transport Phenomena for Copper Systems, Part II

D. B. Butrymowicz, J. R. Manning, and M. E. Read

International Copper Research Association Monograph 8

The Metallurgy of Copper Series

Biweek7y List of Papers on Radiation Chemistry and Photochemistry, Annual Cumulation with Keyword and Author Indexes, Volume 14, 1981

Radiation Chemistry Data Center

University of Notre Dame

Notre Dame, IN 46556 
Biweekly List of Papers on Radiation Chemistry and Photochemistry, Volume 15, 1982

Radiation Chemistry Data Center

University of Notre Dame

Notre Dame, IN 46556

Bulletin of Chemical Thermodynamics, Volume 25

IUPAC Commission on Thermodynamics and Thermochemistry

R. D. Freeman, Editor

Equilibrium Properties of Fluid Mixtures: A Bibliography of Experimental Data on Selected Fluids

M. J. Hiza, A. J. Kidnay, and R. C. Miller 
AAAS American Association for the Advancement of Science

AAPM American Association of Physicists in Medicine (AIP)

ACers American Ceramic Society

ACS American Chemical Society

ADP Automatic data processing

AIChE American Institute of Chemical Engineers

AIP American Institute of Physics

API American Petroleum Institute

APS American Physical Society (AIP)

ASM American Society for Metals

BRS Bibliographic Retrieval Services, Inc:

CAC Center for Analytical Chemistry, NML, NBS

CAPQ Center for Absolute Physical Quantities, NML, NBS

CCE Center for Chemical Engineering, NEL, NBS

CCP Center for Chemical Physics, NML, NBS

CINDAS Center for Information and Numerical Data Analys is and Synthesis, Purdue University

CIS Chemical Information System (NIH/EPA)

CMS Center for Materials Science, NML, NBS

CODATA Committee on Data for Science and Technology (ICSU)

CRR Center for Radiation Research, NML, NBS

CSIN Chemical Substances Information Network (EPA)

DEAP Division of Electron and Atomic Physics (APS)

DIPPR Design Institute for Physical Properties Data (AIChE)

DOE U.S. Department of Energy

EEO Equal Employment Opportunity

EPA U.S. Environmental Protection Agency

FY Fiscal year

GIIGNL Groupe International des Importateurs de Gaz Naturel Liquefie GPE General purpose equipment

GRI Gas Research Institute

IAPS International Association for the Properties of Steam 
ICPEAC International Conference on Physics of Electron and Atomic Collisions

ICSU International Council of Seientific Unions

IFC International Formu?ating Committee (IAPS)

INCRA International Copper Research Association

IUPAC International Union of Pure and Applied Chemistry (ICSU)

JANAF Joint Army, Navy, Air Force (historical acronym)

JCAMP Joint Committee on Atomic and Molecular Physical Data

JILA Joint Institute for Laboratory Astrophysics, NML, NBS-U. of Col.

JPCRD Journal of Physical and Chemical Reference Data

LET Linear energy transfer

LLL Lawrence Livermore National Laboratory

MSDC Mass Spectral Data Centre (UK)

NAS National Academy of Sciences

NBS National Bureau of Standards

NEL National Engineering Laboratory, NBS

NIH National Institutes of Health

NML National Measurement Laboratory, NBS

NRC National Research Council

NSF National Science Foundation

NSRDS National Standard Reference Data System

$O A \quad$ Other agency (funding)

ONR Office of Naval Research

ONWI Office of Nuclear Waste Isolation, Battelle

CSRD Office of Standard Reference Data, MPAL, NBS

PDFC Phase Diagrams for Ceramists Data Center

PL Public law

RCDC Radiation Chemistry Data Center

RPI Rensselaer Polytechnic Institute

STRS Scientific and Technicai Research and Services (anpropriated NBS funds )

USGS United States Geological Survey 


\section{OFFICE OF STANDARD REFERENCE DATA}

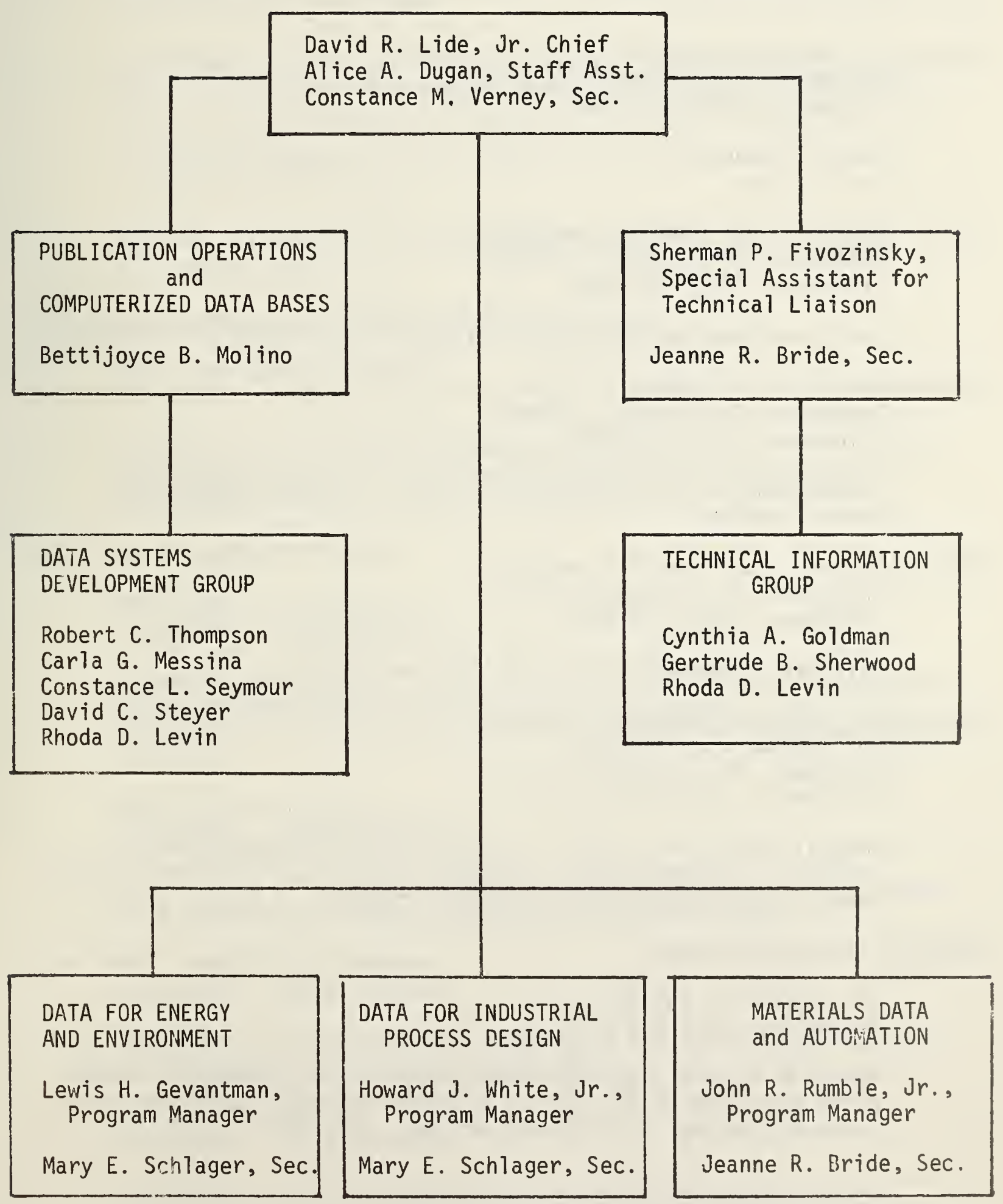


Chief - Dr. David R. Lide, Jr.

Secretary, Ms. Constance M. Verney

Telephone: (301) 921-2467

Overali management of the program; Editor-in-Chief of NSRDS publications

Program Manager - Dr. Lewis H. Gevantman

Secretary, Mrs. Mary E. Schlager

Teiephone: (301) 921-3442

Energy-related data and data related to environment and health

Program Manager - Dr. Howard J. White, Jr.

Secretary, Mrs. Mary E. Schlager

Telephone: (301) 921-2581

Thermochemical and thermophysical data related to industrial process design

Program Manager - Dr. John R. Rumble, Jr.

Secretary, Mrs. Jeanne R. Bride

Telephone: (301) 921-3441

Materials properties data; data base automation

Special Assistant for Technical Liaison -

Dr. Sherman P. Fivozinsky

Secretary, Mrs. Jeanne R. Bride

Telephone: (301) 921-2104

General liaison with users; liaison with publishers regarding promotion of NSRDS output; identification of new areas of activity; supervisor of Technical Information Group

Technica? Information Group

Ms. Cynthia A. Goldman

Telephone: (301) 921-2228

Response to data inquiries from the public; maintenance of NSRDS collection in ma in NBS Library and OSRD Reference Center holdings; inventory control of NSRDS collection; exhibits 
Mrs. Gertrude B. Sherwood

Telephone: (301) 921-2229

Development and maintenance of automated bibliographic systems for NSRDS pubTications; index development; systems for automated production of publication lists and specialized bibliographies

Ms. Rhoda D. Levin

Telephone (301) 921-2229

Response to inquiries from the public; encoding of abstracted materials and editing

Publication Operations and Computerized Data Bases

Mrs. Bettijoyce B. Molino

Telephone: (301) 221-2050

Monitoring of publication procedures; development of on-line data storage and retrieval techniques; supervisor of Data Systems Development Group

Data Systems Development Group

$\mathrm{Mr}$. Robert C. Thompson

Telephone: (301) 921-2554

Computer typesetting of NSRDS publications; interaction with NBS Technical Information and Publications Division on typesetting matters; advice and assistance to data centers on automated data handling

Mrs. Carla G. Messina

Telephone: (301) 921-2554

Development of advanced computer typesetting methods; interactions with Government Printing Office on NSRDS publications

Mrs. Constance L. Seymour

Telephone: (301) 921-2554

Data input and verification; editing of data files; processing of files received from outside data centers

David C. Steyer

Telephone: (301) 921-2050

Programming for conversion of data center files for automated typesetting; development of software for bibliographic and data files in data centers 
Staff Assistant - Mrs. Alice A. Dugan

Telephone: (301) 927-2468

Fiscal and budgetary matters; contracting; procurement; personnel 
APPENDIX D.

Compilation and Evaluation of Radiation Depth Dose Data from Electron Accelerators Used for Radiotherapy: Experiences of a Pilot Data Project in a Hospital Environment, S.P. Fivozinsky and J.A. Purdy, Data for Science and Technology, Proceedings of the Seventh International CODATA Conference, Pergamon Press, 1981

CODATA Directory of Data Sources for Science and Technology, Gerard Emptoz, Editor, Chemical Kinetics Chapter, Lewis H. Gevantman, Editor

Critical Data for Critical Needs, D.R. Lide, Jr., Science 212, June (1980)

Data Bases in Molecular Spectroscopy (Selected Papers from 7th International CODATA Conference), D.R. Lide, Jr., Editor, CODATA Bulletin, No. 40 (Apri1 1981)

Omnidata and Related Software as Developed and Applied by the Office of Standard Reference Data for On-line Retrieval, Analysis, and Manipulation of NSRDS Data Bases, B.B. Molino, Data for Science and Technology, Proceedings of the Seventh International CODATA Conference, Pergamon Press, 1981

Extended Boltzmann Analysis of Electron Swarm Experiments, L. C. Pitchford, S.V. O'Neil, and J.R. Rumble, Jr., Physical Review A23, 294 (1981)

Calculation of Vibrational Excitation of $\mathrm{N}_{2}$ by Electron Impact at 5-50 eV Using Extended-Basis-Set Hartree-Fock Wavefunctions, John R. Rumble, Jr., Donald G. Truhlar, and Michael A. Morrison, Journal of Physics, B, 14, L301

Data Index for Energy Transfer Collisions of Atoms and Molecules - 19701978, J.W. Gallagher, J. Van Blerkhom, E.C. Beaty, J.R. Rumble, Jr., NBS Special Publication 593, April 1981

The Fluid Phase Equilibrium Data Project of the IUPAC Subcommittee on Thermodynamic Tables, H.V. Kehiain, F. Kohler, S. Malanowski and H.J. White, Jr., Data for Science and Technology, Proceedings of the Seventh International CODATA Conference, Pergamon Press, 1981

The National Bureau of Standards and the National Standard Reference Data System, H.J. White, Jr., A Review of AIChE's Design Institute for Physical Properties Data (DIPPR) and Worldwide Affliliated Activities, AIChE Symposium Series No. 203, Vol. 77, 1981

The National Standard Reference Data System, Howard J. White, Jr., Proceedings of the Conference on Flue Gas Desulfurization held at Morgantown, WV, Lawrence Berkeley Laboratory Report, LBL-12342, UC-901, CONF-801176, 1981 
Activities of the NBS Office of Standard Reference Data, Chemical Information System Workshop, ACS Nationa? Meeting, Atlanta, GA., March 1981

Sherman P. Fivozinsky

Quality Control of Data Bases in Medical Practice, Annual Conference on Computer Applications in Medical Care, Washington, D.C., November 1981 Sherman P. Fivozinsky

Thermodynamic Data Bases in the United States--Plans and Progress, ACS National Meeting, Atlanta, GA, March 1981

David R. Lide, Jr.

Quality Control of Data Bases, CSIN Subcommittee, National Library of Medicine, Bethesda, MD, Jüly 1981

David R. Lide, Jr.

Quality Control of Data Bases, Interagency Toxic Substances Data Comimittee, Washington, D.C., October 1981

David R. Lide, Jr.

Federal Databases in the NSRDS: Scope, Trends, Evaluation, Access, Issues, Outlook, American University Institute of Federal Databases, June 1981 Bettijoyce B. Molino

Introduction to Data Processing in an On-Line Environment, ( 2 talks to local high school) December 1980, February 1981 Bettijoyce B. Molino

Discussion of OSRD Computing Requirements, NBS evaluation panel on computing, March 1981 Bettijoyce B. Molino

Vibrational Excitation of $N_{2}$ by Intermediate Energy Electrons, DEAP Meeting of APS, Los Angeles, CA, December 1980 John R. Rumble, Jr.

Comments on Substitution Preparedness Information Stockpile on Critical Materials, Workshop on Conservation and Substitution Technology for Critical Materials, Vanderbilt University, Nashville, TN, June 1981 John R. Rumble, Jr.

Reference Data for Thermophysical Properties, 8th Symposium on Thermophysical Properties, NBS, Gaithersburg, MD, June 1981 John R. Rumble, Jr. (with H. J. White)

Vibrational Excitation of $\mathrm{N}_{2}$ by 5 to $50 \mathrm{eV}$ electrons, XIIth ICPEAC Meeting, Gatlinburg, TN, July 1981

John R. Rumble, Jr. 
Reference Data for Thermophysical Properties, 8th Symposium on Thermophysical Properties, NBS, Gaithersburg, MD, June 1981

Howard J. White, Jr. (with J. R. Rumble)

The Activities of the CODATA Task Group on the Internationalization and Systematization of Thermodynamic Tables, the 36th Annual Calorimetry Conference, NBS, Gaithersburg, MD, October 1981

Howard J. White, Jr. 
David R. Lide, Jr.

Overseer's Visiting Committee, Department of Chemistry, Harvard University

Council of the American Physical Society (APS)

Audit Committee, APS

Committee on Fellowships, Division of Chemical Physics, APS

Committee on Meetings, APS

1981 Irving Langmuir Prize Committee, APS

American Institute of Physics (AIP) Publication Board

Subcommittee on an Anniversary Physics Handbook (Chairman), AIP's 50th Anniversary Celebration Committee

Committee on Nomenclature, ACS

Division of Physical Chemistry, ACS (Alternate Councilor)

Chemical Abstracts Advisory Board, ACS

Section Committee, Chemistry, AAAS

Petroleium Research Fund Advisory Board, ACS

Journal of Physical and Chemical Reference Data (Editor)

Committee on Data for Science and Technology of Internatiorial Council of Scientific Unions (U.S. Delegate to CODATA \& Member of Executive Committee)

CODATA Publication Committee (Chairman)

CODATA Bulletin (Associate Editor)

Program Committee for Eighth International CODATA Conference Joint Committee on Atomic and Molecular Physical Data (JCAMP)

Interdivisional Committee on Nomenclature and Symbols, IUPAC Commission on Symbols, Terminology, and Units, IUPAC (Chairman) 
Ad hoc Panel on Issues of Science Communication (NAS/NRC)

Ad hoc Panel on Information Science and Science Information (NAS/NRC)

Physical Chemistry Division, IUPAC (Vice-President)

Chemical Information System (CIS) Steering Committee

NAS/NRC Committee on Atomic and Molecular Science

Program Committee, Second International Conference on Precision Measurement and Fundamental Constants

\section{Lewis H. Gevantman}

IUPAC Commission V.8 on Solubility Data (Co-Secretary)

Source Selection Board, Department of the Army, Medical Bioengineering Research and Development Laboratory

Executive Committee, Joint Committee on Atomic and Molecular Physical Data

Subcommittee on the Chemical Substance Information Network (CSIN)

Basic Nuclear Data Committee of the National Nuclear Data Center (Observer)

Reference Nuclear Data Committee of the National Nuclear Data Center (Observer)

Subcommittee on Batteries of the Advisory Committee on Energy Storage to the Department of Energy

Howard J. White, Jr.

International Association for the Properties of Steam, (Executive Secretary)

Task Group on the Internationalization and Systematization of Thermodynamic Tables (CODATA/ICSU) (Chairman)

Subcommittee on Thermodynamic Tables, Commission on Thermodynamics, International Union of Pure and Applied Chemistry (IUPAC) (Secretary)

Engineering Sciences Data Unit, Ltd. (Corresponding Member) 
Research Committee on the Properties of Steam, American Society of Mechanical Engineers (Secretary)

Design Institute for Physical Properties Data (AIChE)

Administrative Committee

Technical Committee (non voting)

Liaison Committee

Data Compilation Project Advisory Committee

Data Book Project Advisory Committee

Electrolyte Data Project Advisory Committee

American Petroleum Institute Subcommittee on Technical Data (Advisor)

John R. Rumble, Jr.

NAS/NRC National Materials Advisory Board, Committee on Materials

Information Used in Computerized Structural Design and Manufacturing Liaison Member)

Sherman P. Fivozinsky

AAPM Medical Physics Data Group

Task Group on Accessibility and Dissemination of Data (CODATA/ICSU) (Secretary)

Bettijoyce B. Molino

Computer Users Advisory Committee (NBS)

Program Committee for the ACS Chemical Information Division

\section{Alice A. Dugan}

NML Administrative Council

NML-EEO Women's Personnel Panel, NBS 
March 27, 1981

Opportunities for Generation and Exploitation of Thermochemical Data, T.I. Barry, National Physical Laboratory, Teddington, Middlesex, U.K.

April 15, 1981

The Atomic and Molecular Data for Fusion Program of the IAEA-Perspectives and Problems, J.R. Rumble, Jr., National Bureau of Standards, Washington, D.C.

June 12, 1981

On-line Access to the Thermodynamic Data Bank at the University of Toronto, C. B. Alcock, University of Toronto, Toronto, Cánada

July 6,1981

Assessed Atomic Data, F.J. Smith, The Queen's University of Belfast, Belfast, Northern Ireland

August 12, 1981

Studies of Surfaces by Electron Spectroscopy, C.N.R. Rao, Indian Institute of Science, Bangalore, India

November 2, 1981

FACT-An on-7ine Chemical Thermodynamic Information System, Arthur Pelton, University of Montreal, Montreal Quebec, Canada

December 8, 1981

Fu11 Text Searching of ACS Journals, Seldon Terrent, American Chemical Society, Washington, D.C. 


\author{
Public Law 90-396 \\ 90 th Congress, H. R. 6279 \\ July 11, 1968
}

\title{
An Alt
}

To provide for the collection, compilation, critical evaluation, publication, and sale of standard reference data.

Be it enacted by the Senate and House of Representatives of the Onited States of America in C'ongress assembled,

Standard Refere enoe Data Aot.

\section{DECLARATION OF POLICY}

Secrion 1. The Congress hereby finds and declares that reliable standardized scientific and technical reference data are of vital importance to the progress of the Nation's science and technology. It is therefore the policy of the Congress to make critically evaluated reference data readily available to scientists, engineers, and the general public. It is the purpose of this Act to strengthen and enhance this policy.

\section{DEFINITIONG}

SEc. 2. For the purposes of this Act-

(a) The term "standard reference data" means quantitative inforination, related to a measurable physical or chemical property of a substance or system of substances of known composition and structure, which is critically evaluated as to its reliability under section 3 of this Act.

(b) The term "Secretary" means the Secretary of Commerce.

SEC. 3. The Secretary is authorized and directed to provide or arrange for the collection, compilation, critical evaluation, publication, and dissemination of standard reference data. In carrying out this program, the Secretary shall, to the maximum extent practicable, utilize the reference data services and fucilities of other agencies and instrumentalities of the Federal Government and of State and local governments, persons, firms, institutions, and associations, with their consent and in such a manner as to a void duplication of those services and facilities. All agencies and instrumentalities of the Federal Govemment are encouraged to exercise their duties and functions in such manner as will assist in carrying out the purpose of this Act. This section shall be deemed complementary to existing authority, and nothing herein is intended to repeal, supersede, or diminish existing authority or responsibility of any agency or instrumentality of the Federal Government.

SEC. 4. To provide for more effective integration and coordination of standard reference data activities, the Secretary, in consultation with other interested Federal agencies, shall prescribe and publish in the Federal Register such standards, criteria, and procedures for the preparation and publication of standard reference data as may be necessary to carry out the provisions of this Act.

SEC. 5. Standard reference data conforming to standards established by the Secretary may be made available and sold by the Secretary or by a person or agency designated by him. To the extent practicable and approprinte, the prices established for such data may reflect the cost of collection, compilation, evaluation, publication. and dissemination of the data, including administrative expenses; and the amounts received shall be subject to the Act of March 3,1901 , as amended (15 .C.S.C. $271-2 \pi 8 \mathrm{e})$.

SEC. 6. (a) Notwithstanding the limitations contained in section 8 of title 17 of the United States Code, the Secretary may secure copyright and renewal thereof on behals of the linited States as author or proprietor in all or any part of any standard reference data which standard refer enoe data.

Standards, etc. Publication in Federel Reglster.

Sale of refer enoe data. Cost reoovery.

31 stat. I449; Ante, p. 34. U. S. oopyng ght and renewal rights. 61 Stat. 655 ; 76 Stat. 446. 


\begin{abstract}
Pub. Law 90-396 - 2- July 11, 1968
82 STAT. 340

he prepares or niakes available under this Act, and may authorize the reproduction and publication thereof by others.

(b) The publication or republication by the Government under this tct, either separately or in a public document, of any material in which copyright is subsisting shall not be taken to cause any abridgment or annulment of the copyright or to authorize any use or appropriation of such muterial without the consent of the copyright proprietor.

Appropriation. SEc. 7. There are authorized to be appropriated to carry out this Act, $\$ 1.86$ million for the fiscal year ending June 30,1969 . Not.withstanding the provisions of any other law, no appropriations for any fiscal year may be made for the purpose of this Act after fiscal year 1969 unless previously authorized by legislation hereafter enacted by the Congress.

Short t1 tle. Src. 8. This Act may be cited as the "Standard Reference Data Act."

Approved July 11, 1968.
\end{abstract}

LEGISLATIVE HISTORY:

HOUSE REPORT No, 260 (Comw, on Soience and Astronautic8).

SENATE REPORT No. 1230 (Comm, on Commeroe).

CONGRESSIONAL RECORD:

Vol. 113 (1967): Aug, 14, oonsidered and passed House.

Vo1. 114 (1968): June 13, oonsidered and pessed Senate, amended.

June 27, House conourred in Senate

gmendments. 


\section{NSRDS DATA CENTERS}

Alloy Phase Diagram Data Center

Dr. Robert Mehrabian

Center for Materials Science

Materials B1dg. - Room B266

National Bureau of Standards

Washington, D.C. 20234

Telephone: (301) 921-2811

Aqueous Electrolyte Data Center

Dr. B. R. Staples

Center for Thermodynamics and Molecular Science

Chemistry B1dg. - Room A764

National Bureau of Standards

Washington, D.C. 20234

Telephone: (301) 921-3632

Atomic Collision Cross Section Information Center

Dr. Jean Gallagher/Acting

Joint Institute for Laboratory Astrophysics

University of Colorado

Boulder, Colorado 80309

Telephone: (303) 492-7801

Atomic Energy Levels Data Center

Dr. W. C. Martin

Center for Radiation Research

Physics B7dg. - Room A167

National Bureau of Standards

Washington, D.C. 20234

Telephone: (301) 921-2011

Atomic Transition Probabilities Data Center

Dr. W. L. Wiese

Center for Radiation Research

Physics B7dg. - Room A267

National Bureau of Standards

Washington, D.C. 20234

Telephone: (301) 921-2071 
Center for Information and Numerical Data Analysis and Synthesis (CINDAS)

\author{
Dr. C. Y. Ho \\ Purdue University \\ CINDAS \\ 2595 Yeager Road \\ West Lafayette, Indiana 47906 \\ Telephone: (317) 494-6300 \\ Direct inquiries to: Mr. W. H. Shafer
}

Chemical Kinetics Information Center

Dr. R. F. Hampson, Jr.

Center for Thermodynamics and Molecular Science

Chemistry B1dg. - Room A166

National Bureau of Standards

Washington, D.C. 20234

Telephone: (301) 921-2565

Chemical Thermodynamics Data Center

Dr. David Garvin

Center for Thermodynamics and Molecular Science

Chemistry B1dg. - Room A152

National Bureau of Standards

Washington, D.C. 20234

Telephone: (301) 921-2773

Crystal Data Center

Dr. A. D. Mighel1

Center for Materials Science

Materials B1dg. - Room A221

National Bureau of Standards

Washington, D.C. 20234

Telephone: (301) 921-2950

Diffusion in Metals Data Center

Dr. John R. Manning

Center for Materials Science

Materials B1dg. - Room A153

National Bureau of Standards

Washington, D.C. 20234

Telephone: (301) 921-3354 
Fluid Mixtures Data Center

Mr. N. A. 07 ien

Center for Chemical Engineering

National Bureau of Standards

Boulder, Colorado 80303

Telephone: (303) 497-3257

Fundamental Constants Data Center

Dr. Barry N. Taylor

Center for Absolute Physical Quantities

Metrology B1dg. - Room B258

National Bureau of Standards

Washington, D.C. 20234

Telephone: (301) 921-2701

*Fundamental Particle Data Center

Dr. Robert Kelly

Lawrence Berkeley Laboratory

University of California

Berkeley, California 94720

Telephone: (415) 486-5885

*High Pressure Data Center

Dr. Leo Merril1

P.0. Box 7246

University Station

Provo, Utah 84602

Telephone: (801) 378-4442

Ion Energetics Data Center

Dr. Sharon Lias

Center for Thermodynamics and Molecular Science

Chemistry B7dg. - Ruom A139

National Bureau of Standards

Washington, D.C. 20234

Telephone: (301) 927-2439

*Isotopes Project

Dr. Janis Dairiki

Lawrence Berkeley Laboratory

University of California

Berkeley, California 94720

Telephone: (415) 486-6152 
JANAF Thermochemical Tables

Dr. Malcolm W. Chase

Dow Chemical Company

1707 Building

Thermal Research Laboratory

Midland, Michigan 48640

Telephone: (517) 636-4160

Molecular Spectra Data Center

Dr. F. J. Lovas

Center for Thermodynamics and Molecular Science

Physics B1dg. - Room B268

National Bureau of Standards

Washington, D.C. 20234

Telephone: (301) 921-2023

Molten Salts Data Center

Dr. G. J. Janz

Rensselaer Polytechnic Institute

Department of Chemistry

Troy, New York 12181

Telephone: (518) 270-6344

National Center for Thermodynamic Data of Minerals

Dr. John L. Haas, Jr.

U.S. Geological Survey

U.S. Department of the Interior

959 National Center

Reston, Virginia 22092

Telephone: (703) 860-6911

Phase Diagrams for Ceramists Data Center

Dr. Lawrence P. Cook

Center for Materials Science

Materials B1dg. - Room A227

National Bureau of Standards

Washington, D.C. 20234

Telephone: (301) 921-2844

Photon and Charged-Particle Data Center

Dr. Martin J. Berger

Center for Radiation Research

Radiation Physics B1dg. - Room C313

National Bureau of Standards

Washington, D.C. 20234

Telephone: (301) 921-2685 
Radiation Chemistry Data Center

Dr. Alberta B. Ross

University of Notre Dame

Radiation Laboratory

Notre Dame, Indiana 46556

Telephone: (219) 283-6527

Thermodynamics Research Center

Dr. Kenneth R. Hall

Thermodynamics Research Center

Texas A \& M University

College Station, Texas 77843

Telephone: (713) 846-8765 or 845-4971

Thermodynamic Research Laboratory

Dr. Buford Smith

Department of Chemical Engineering

Washington University

St. Louis, Missouri 63130

Telephone: (314) 863-0100

*The Office of Standard Reference Data is not involved at the present time in the administration or funding of these data centers but assists in making their outputs and services known to the scientific community. 


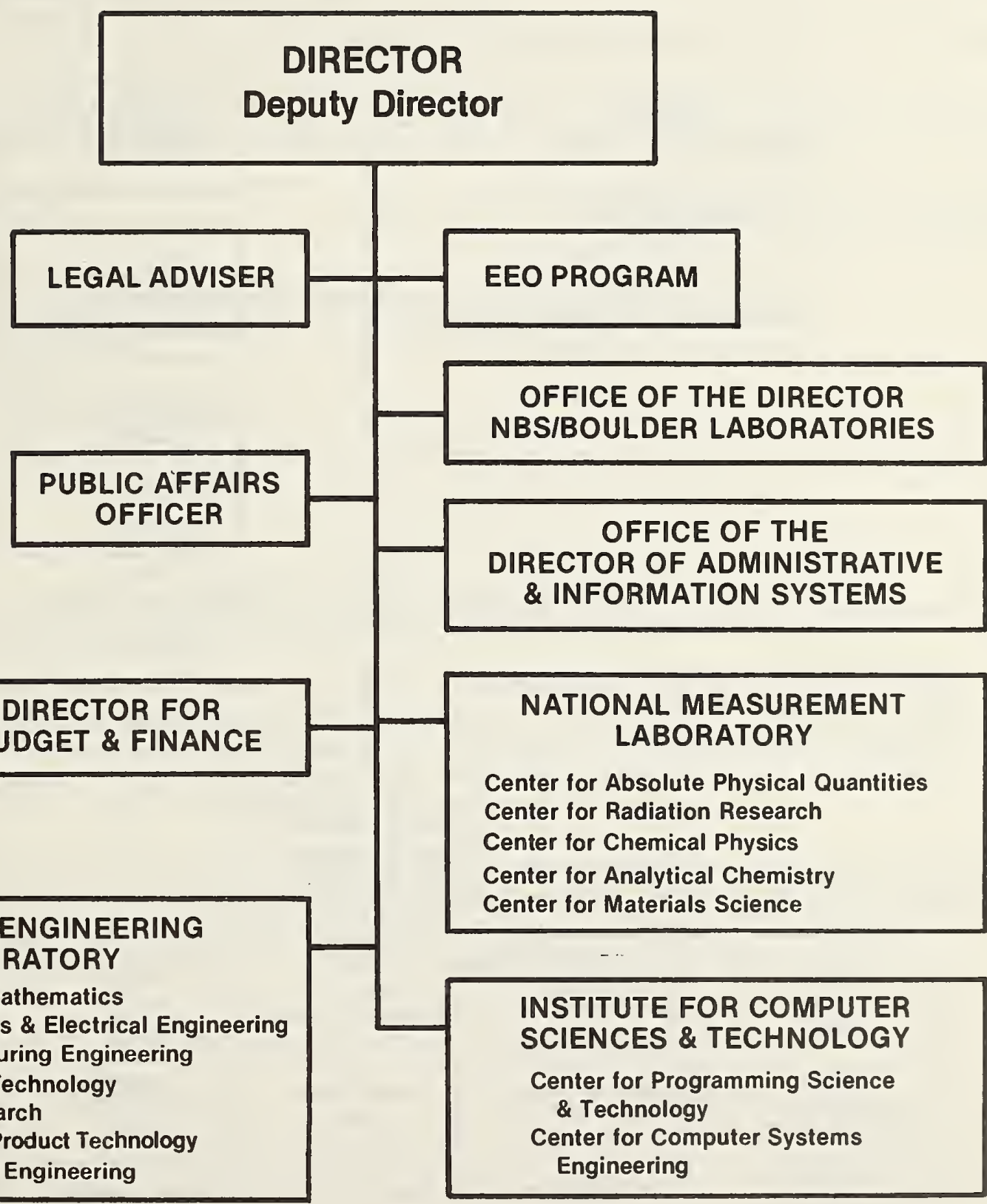




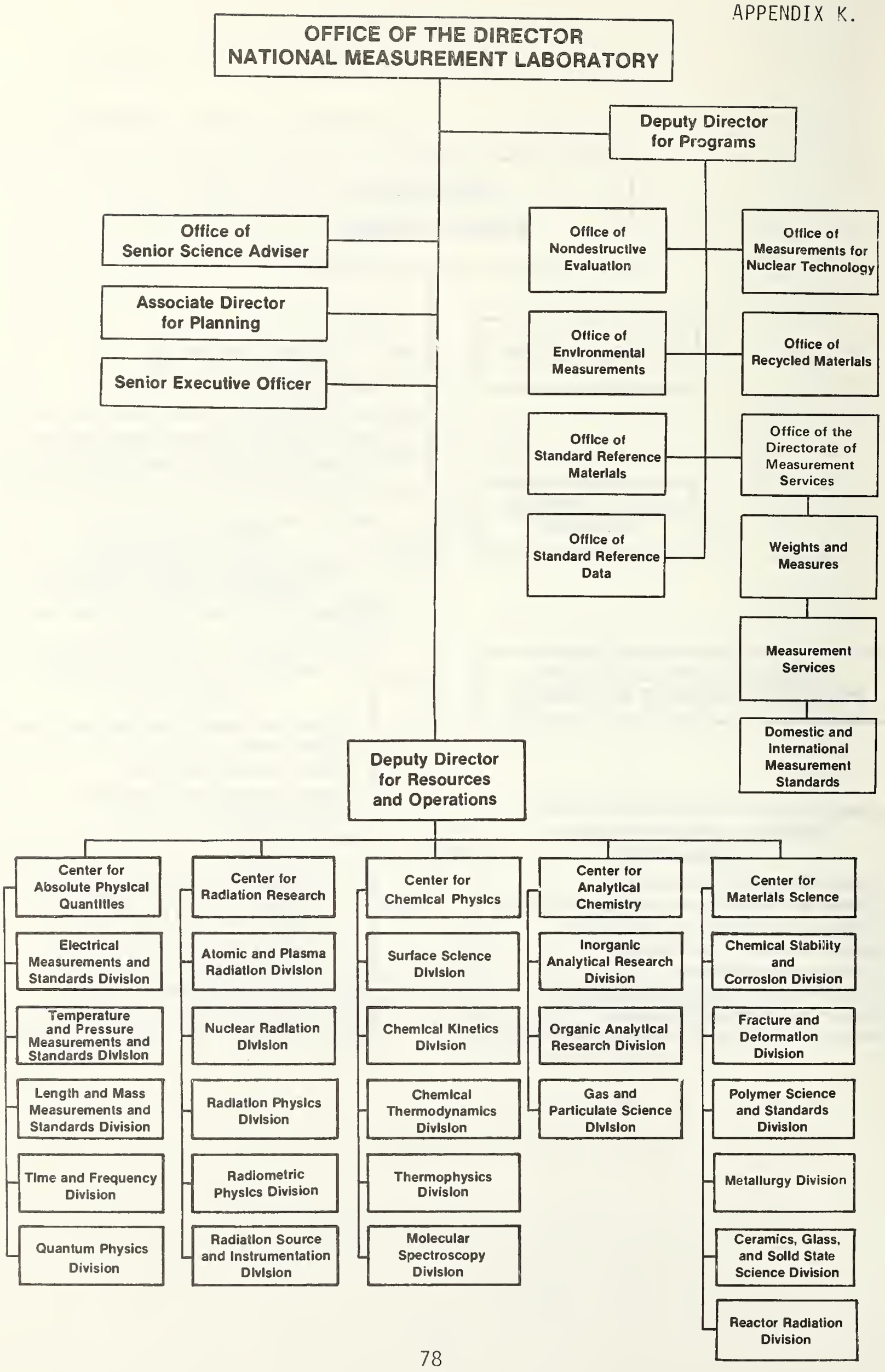


NBS.114A (REV. 2.8C)

U.S. DEPT. OF COMM.

1. PUBLICATION OR

BIBLIOGRAPHIC DATA

SHEET (See in structions) REPORT NO.

NBSIR $81-2442$

4. TITLE AND SUBTITLE

Technical Activities 1981

Office of Standard Reference Data

5. AUTHOR(S)

S. P. Fivozinsky, Editor

6. PERFORMING ORGANIZATION (If joint or other than NBS, see instructions),

7. Contract Grant No.

NATIONAL BUREAU OF STANDARDS

DEPARTMENT OF COMMERCE

WASHINGTON, D.C. 20234

8. Type of Report \& Period Covered

9. SPONSORING ORGANZATION NAME AND COMPLETE ADDRESS (StFeet, CHY, SlOte, ZIP)

National Bureau of Standards

Department of Commerce

Washington, D.C. 20234

10. SUPPLEMENTARY NOTES

Document describes a computer program; SF-185, FIPS Software Summary, is attached.

11. ABSTRACT (A 200-word or less factual summary of most significant information. If document includes a significant bibliography or literature survey, mention it here)

The Office of Standard Reference Data is one of six program offices in the National Measurement Laboratory, National Bureau of Standards. The Standard Reference Data Program develops and disseminates data bases of critically evaluated physical/chemical properties of substances. These data bases are available through NBS and private publications, on magnetic tape, and from on-line retrieval systems.

The Office of Standard Reference Data is responsible for management and coordination of the program. Work is carried out through a decentralized network of data centers and projects referred to as the National Standard Reference Data System (NSRDS). This volume summarizes the activities of the program for the year 1981.

12. KEY WORDS (Six to twelve entries; alphabetical order; capitalize only proper names; and separate key words by semicolons) data compilation; energy and environmental data; evaluated data; materials data; standard reference data; technical activities 1981 ; thermochemical and thermophysical data

13. AVAILABILITY

[X] Unlimited

[ For Official Distribution. Do Not Release to NTIS

$\square$ Order From Superintendent of Documents, U.S. Government Printing Office, Washington, D.C. 20402.

[] Order From National Technical Information Service (NTIS), Springfield, VA. 2216I

14. NO. OF

PRINTED PAGES

80

15. Price

9.50 

